Research Article

\title{
Dynamic Simulation Analysis on Axle Spline of High-Speed Train Gauge-Change System
}

\author{
Jinyi Bai $\mathbb{D}$, ${ }^{1}$ Wenjing Wang $\mathbb{D}^{1},{ }^{1}$ Pingyu Zhou $\mathbb{D}{ }^{2}$, and Yuguang Wang $\mathbb{D}^{2}$ \\ ${ }^{1}$ School of Mechanical, Electronic and Control Engineering, Beijing Jiaotong University, Beijing 100044, China \\ ${ }^{2}$ CRRC Qing Dao SiFang Co., Ltd., Qingdao 266111, China \\ Correspondence should be addressed to Wenjing Wang; wjwang@bjtu.edu.cn
}

Received 15 September 2020; Revised 28 January 2021; Accepted 10 February 2021; Published 10 April 2021

Academic Editor: Matteo Filippi

Copyright $\odot 2021$ Jinyi Bai et al. This is an open access article distributed under the Creative Commons Attribution License, which permits unrestricted use, distribution, and reproduction in any medium, provided the original work is properly cited.

Spline couplings are widely used in transmission systems to transfer torque due to their higher load carrying capacity and better durability performance. Most researches are conducted under static and quasistatic loading cases; however, very little is known about their contact behavior and stress distribution under dynamic loading cases, especially as a key transmission component between wheel and axle. In this paper, a 3D dynamic contact and impact analysis model of the wheel-axle spline of high-speed train gauge-change system is employed in order to investigate the effect of driving velocity and assembling error and vibration on spline couplings. Three categories of loading cases are considered: (i) $0.3 \mathrm{~m} / \mathrm{s}^{2}$ driving rate representing quasistatic loading case; (ii) $0.5 \mathrm{~m} / \mathrm{s}^{2}$ driving rate representing normal loading case, and (iii) $1 \mathrm{~m} / \mathrm{s}^{2}$ driving rate representing exceptional loading case. Aside from this, influence of spline misalignment, including radial misalignment and circumferential misalignment, has been investigated under normal loading case. Numerical results for surface integral contact analysis conducted by LS-DYNA and MATLAB were presented and compared for the verification of the results.

\section{Introduction}

Splines have the characteristics of high efficiency and stability performance due to their larger pressure angles and shorter tooth height, which can satisfy various complicated engineering environments. However, this feature would be compromised due to the complicated loading conditions and manufacturing error. Moreover, tooth indexing or space error due to the asymmetric clearance can also notably affect stress distribution patterns and engagement behaviors of spline coupling.

The automatic gauge-changing wheelset system of highspeed train shown in Figure 1 has a far more complicate construction than a wheelset used for the standard gauge. It consists of the following parts:

the axle

the wheels

the locking pins

the axle bearings with casings the external sleeves

the internal sleeves

the stopper rings

the axle boxes

the axle splines

the wheel splines

The wheelsets can adapt to two different rail gauges $(1435 / 1520 \mathrm{~mm})$. Wheel gauge changes automatically adjusting to the required track gauge when a train passes the rail gauge-change stand.

The core component of this system that transmits torque is the wheel-axle spline, which is completely different from the conventional structure. Thus, many works developed the analytical and computational models to discuss contact stress distribution along the axial or profile direction of the spline tooth. Barrot [1-3] proposed a method to estimate the load distribution under pure torsional torque. Despite many hypotheses that existed in this model, such as teeth geometry is standardization, 


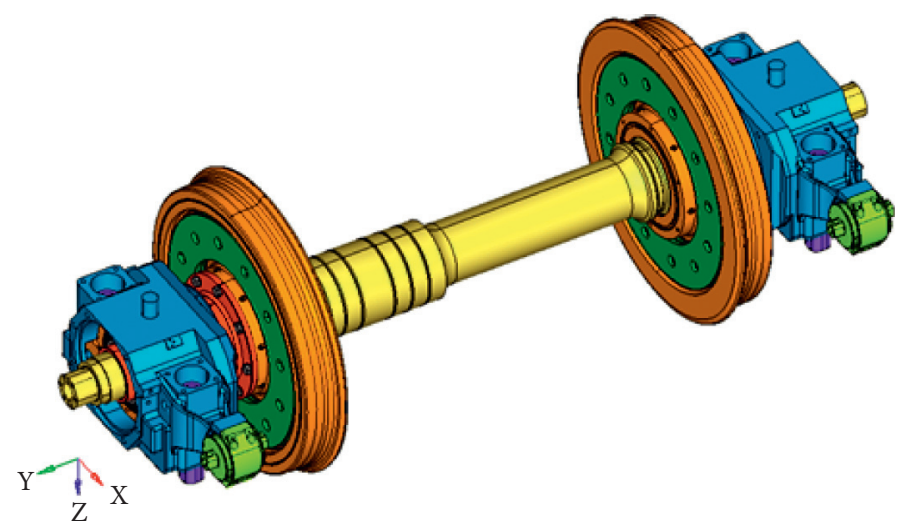

FIGURE 1: Basic elements of the automatic gauge-changing wheelset system.

dimensions are nominal and no friction existed between engagement teeth; however, this research still illustrates the radial distribution of the contact pressure and further conducts the relationship between torsional stiffness and various displacement components. Volfson [4] provided a rough estimation of contact stress distribution under typical pure torsional and bending loading cases, as distinct from known approaches, the author considered in detail five stress factors that contributed to the fracture of the splined shaft. Besides, Chase [5] introduced the manufacturing tolerances to the nominal system and established a new model to verify the tooth deflections and engagement sequence.

Aside from these analytical models, recently, finite element (FE) and boundary element (BE) are accepted and adopted by many scholars. Medina and Olver $[6,7]$ studied the evolution of slip and pressure of misalignment teeth under a steady torque by using a BE based simulation model. Adey et al.[8] illustrated the development of analysis tools for the spline couplings. This model had the function that can predict the contact stress and acquire the torsional transfer mechanism. Leen et al.[9-11] developed a three-dimensional frictional contact model for a high-performance aero-engine spline coupling, which accounted for the load distribution under various combined loading cases. Hong et al [12-14] proposed a finite-element model of a gear-shaft system under combined torsional load, radial load, and tilting moment, which calculated the load distribution of tooth interface by using a commercial FE based contact mechanics model.

Due to the presence of manufacturing tolerances in the actual situation and other complicated inevitable effects such as wear, impact, and misalignment. Another group of studies adopted the combination of simulation and experimental methods. Limmer et al [15] and Tjernberg [16, 17] presented load distribution of a spline coupling between a shaft and a sleeve by using both analytical and FE models. Further, the residual stress on the shaft surface and stress concentration factor is measured by the fatigue test. Curà [18] developed a special hexapod measuring device to obtain the experimental values of spline coupling tooth stiffness, and the influence of angular misalignments between hub and shaft also investigated in the experimental planning. Hu et al. [19] built a nonlinear dynamic model of the spline-gear system to discuss the effect of assembly methods on spline couplings. Amarnath [20] and Munro [21] presented a method that allows the accurate measurement of tooth pair stiffness; the former also analysed the effect of lubricant film thickness.

The above literature review indicates that most of the studies were based on static or quasistatic loads. That is, these researches did not consider the dynamic behavior of spline in the process of contact and separation. Along with the time-varying loading cases, the consequences of introducing an intentional misalignment to splines also remain unknown. Further, the effects of system vibration are also unclear. As such, for the wheel-axle-spline system, an efficient and accurate spline model that accounts for effects of transient impact and influences of vibration is required. Accordingly, this paper aims at investigating the effect of loading rate, assembling error, and system vibration on the impact behavior of spline couplings.

\section{Finite-Element Model of Wheel-Axle Splines}

Figure 2 shows the finite-element model of the entire wheel sets. To overcome the extremely large simulation time for the transient, nonlinear finite-element model, a simplified alternative model is considered, shown in Figure 3. The simplified model consists of an elastic part and a rigid part. The loads and constraints are applied to the model through the rigid part, while the elastic part contains the parameters such as contact type and friction coefficient.

Figure 4(a) shows an entire view of the axle spline at a certain time to demonstrate the loads carried by individual contact grid cell on each tooth. Since this method cannot reflect tooth load distribution and important information in real time, the contact surface of teeth of the axle spline is divided with grids to output-related data, as shown in Figure 4(b). Over this potential contact area, the model uses a contact grid with $X$ number of elements in the profile direction and $Y$ number of elements along the axial direction. Thus, real-time load distribution, rotating speed, and meshing force were extracted from the grid nodes in a rectangular window. Using this method, related data mentioned above on all of the teeth can be viewed simultaneously and conveniently. 


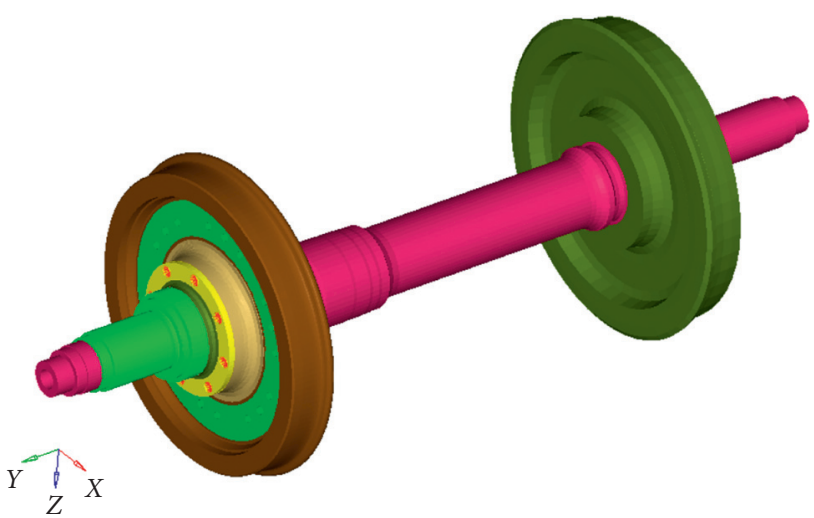

Figure 2: Entire wheel sets and axle finite-element model.

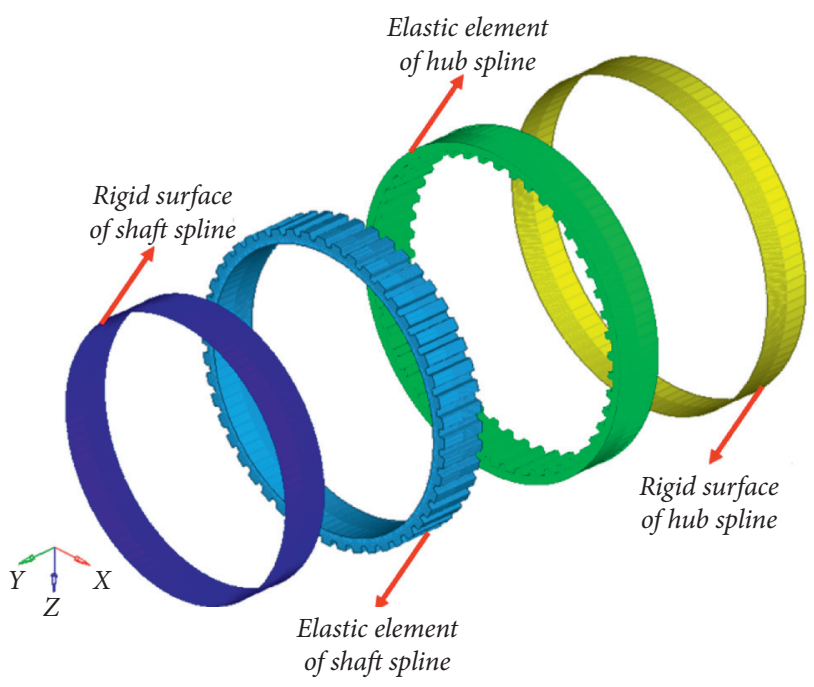

FIgURE 3: Simplified wheel-axle spline finite-element model.

This simplified spline model is used to analyze the load distribution of splines under transient and vibration loads. The loading method considered in this study represents the case of a spline coupling driven by a motor at different velocities; an angular velocity $\omega$ is applied to the centroid of the axle spline as shown in Figure 5 while the outer face of sleeve is applied resistance moment $T$, the translational motions along $x, y$, and $z$ and rotational motions along $x$ and $z$ directions of both external and inner splines are constrained, which represent a purely rotating load with no radial movement and tilting moment. For the first situation, all the clearance of spline tooth remains identical (ideal situation) in the process discussing the effect of driving rate, while for the second situation as shown in Figures 6(a) and 6(b), intentional radial and circumferential misalignment are introduced to the nominal system (normal situation), respectively, where the boundary condition remains unchanged.

\section{Computational Method}

Assume that two rigid-body contacts and then the impactcontact force are defined as $[22,23]$

$$
f= \begin{cases}K x^{e}+F_{s}(x, 0,0, d, C) x, & x<0, \\ 0, & x \geq 0,\end{cases}
$$

where $K$ is stiffness coefficient, $x$ is distance variable of two contacting object, $e$ is nonlinear index, $F_{s}$ is step function, $C$ is damping coefficient, and $d$ is breakdown depth at maximum damping situation.

Here, $x \geq 0$ means no contact between these two objects and $f$ remains zero, while $x<0$ means contact happened and $f$ is determined by the following parameters.

It is observed that the impact-contact force comprises two parts according to equation (1), which is elastic component $K_{x}^{e}$ and damping component $F_{s}(x, 0,0, d, C)$.

For stiffness coefficient $K$,

$$
K=\frac{4}{3} \sqrt{\frac{R_{1} R_{2}}{R_{1}+R_{2}}} E^{*},
$$

where $R_{1}$ and $R_{2}$ are the equivalent radii of two object at the contact point, due to the small deformation in engagement process. $R_{1}$ and $R_{2}$ are defined as their pitch circle radius.

For elastic modulus $E^{*}$,

$$
E^{*}=\frac{E_{1} E_{2}}{E_{1}\left(1-v_{2}^{2}\right)+E_{2}\left(1-v_{1}^{2}\right)},
$$

where $E_{1}$ and $E_{2}$ are the elastic moduli of two object materials, and $v_{1}$ and $v_{2}$ are the Poisson's ratio of two object materials.

For function $F_{s}$,

$$
\begin{array}{rlr}
F_{s}\left(x, x_{0}, h_{0}, x_{1}, h_{1}\right) & = \begin{cases}h_{0}, & x \leq x_{0}, \\
h_{0}+a(3-2 \Delta) \Delta^{2}, & x_{0}<x<x_{1}, \\
h_{1}, & x>x_{1},\end{cases} \\
a & =h_{1}-h_{0}, \\
\Delta & =\frac{x-x_{0}}{x 1-x_{0}},
\end{array}
$$

where $x$ is independent variable of function $F_{s}, x_{0}$ is initial value of $x, h_{0}$ is initial value of function $F_{s}, x_{1}$ is final value of $x$, and $h_{1}$ is final value of function $F_{s}$.

Moreover, the obvious deformation mainly occurs in the contact area of spline teeth. According to the Hertz contact theory, the distance $x$ can conduct by the following formula:

$$
x=\left(\frac{9 p^{2}}{16 R E^{* 2}}\right)^{1 / 3},
$$

where $p$ is load applied to the object.

As described above, the impact-contact force can be obtained by those relative parameters. Besides, for the deformable-body model, the transient dynamic equilibrium equation for a contact-impact problem is shown as follows:

$$
M_{i} \ddot{U}_{i}+C_{i} \dot{U}_{i}+K_{i} U_{i}=F_{i},
$$




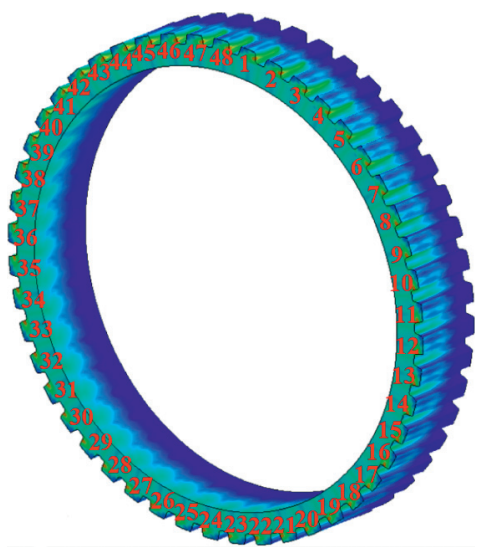

(a)

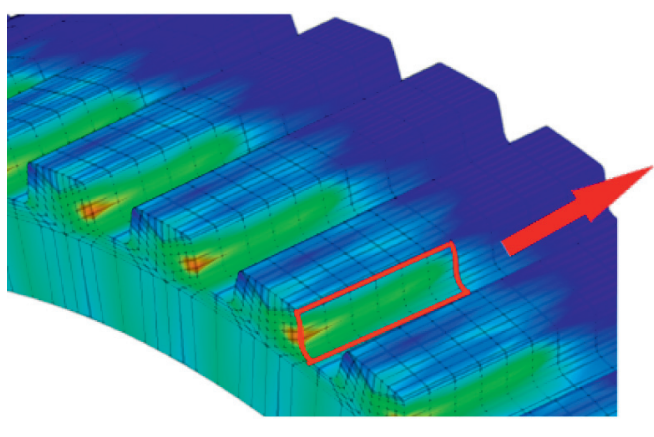

(b)

FIGURE 4: Stress distribution of axle spline under a certain loading case. (a) Overall contact status of axle spline. (b) Local contact surface of grids of axle spline.

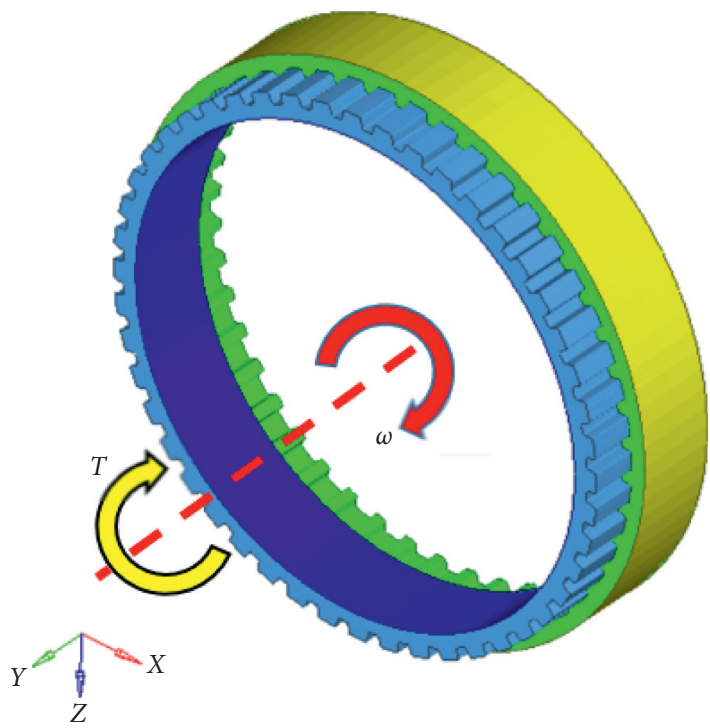

FIgURe 5: The loading method for wheel-axle spline.

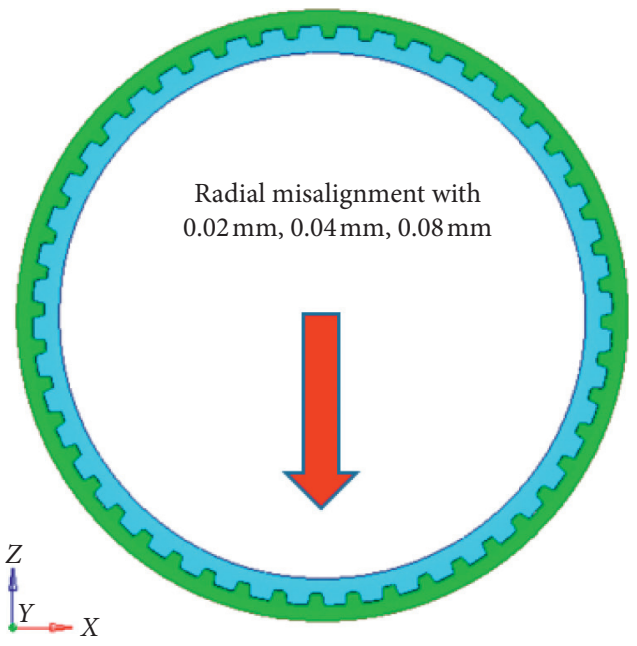

(a)

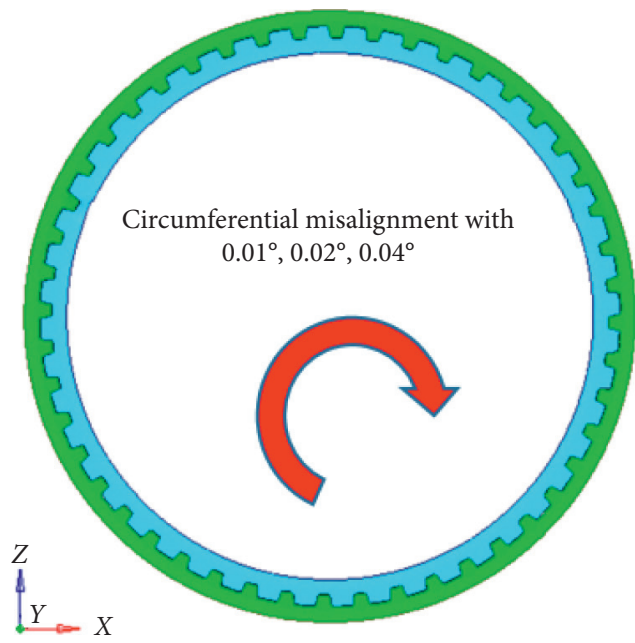

(b)

Figure 6: Two spline finite-element model with intentional misalignment: (a) radial misalignment; (b) circumferential misalignment. 


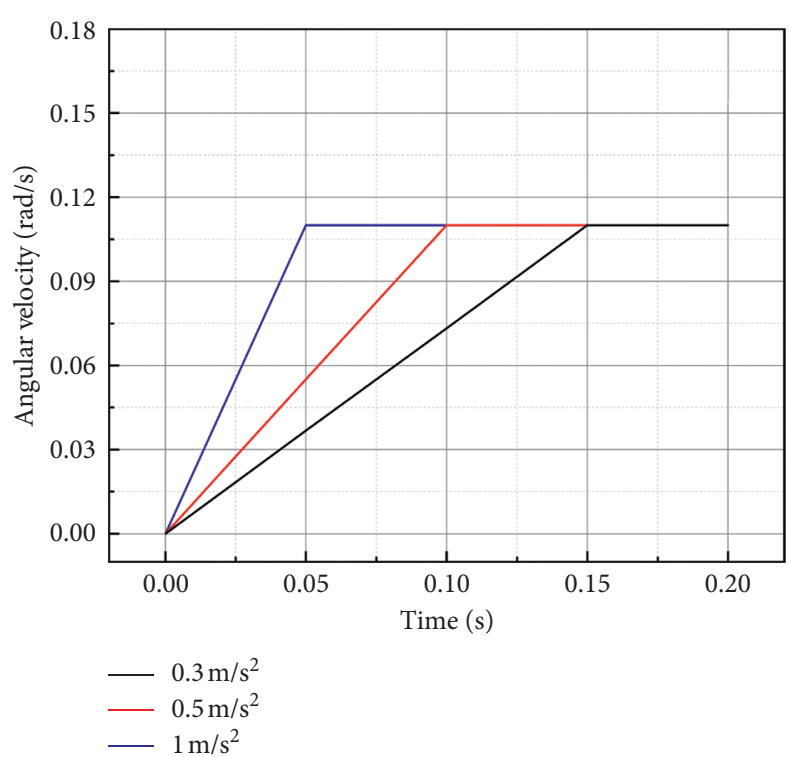

(a)

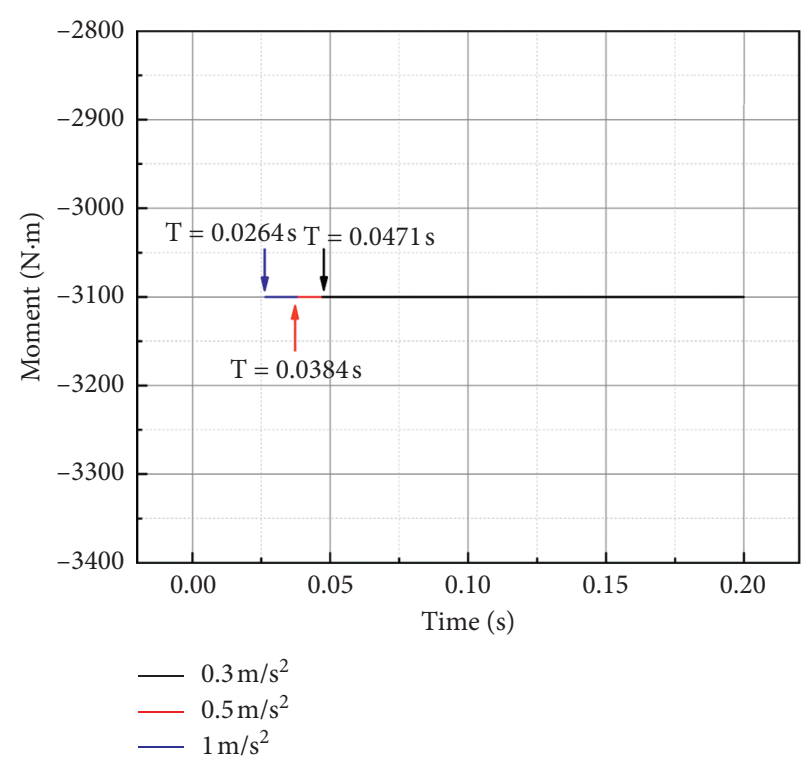

(b)

Figure 7: The load curve of axle spline and wheel spline. (a) The inner surface of axle spline load curves. (b) The outer surface of wheel spline load curves.

where $M_{i}, C_{i}$, and $K_{i}$ are the mass, damping, and stiffness matrix of the element, respectively. $F_{i}$ is the contact force vector of the structure. $U_{i}, U_{i}$, and $U_{i}$ are the displacement, velocity, and acceleration vector of the structure. Here, Rayleigh's damping model is applied in the form

$$
C=\alpha_{0} M+\alpha_{1} K
$$

where $\alpha_{0}$ and $\alpha_{1}$ are constant coefficients that can be obtained through experiment.

For the nonlinear problems, only numerical solutions are possible; an efficient and accurate solver LS_DYNA is used in this paper which adopts a modification method of central difference time integration. A remarkable difference between explicit and implicit methods is that for explicit schemes, the equation of motion is evaluated at the old time step $t_{n}$, whereas implicit methods use the equation of motion at the new step $t_{n+1}$.

Assume that the initial displacements, velocities, and accelerations in the time series of $t_{0}, t_{1}, t_{2} \ldots t_{n}$ are obtained; then the response at $t_{n+1}(t+\Delta t)$ can be acquired by the following equations.

The difference formula for $\ddot{U}$ and $\dot{U}_{i}$ is assumed:

$$
\left\{\begin{array}{l}
\ddot{U}_{i}=\frac{1}{\Delta t^{2}}\left(U_{t-\Delta t}-2 U_{t}+U_{t+\Delta t}\right), \\
\dot{U}_{i}=\frac{1}{2 \Delta t}\left(-U_{t-\Delta t}+U_{t+\Delta t}\right) .
\end{array}\right.
$$

Substituting equation (8) in equation (6),

$$
\left(M+\frac{1}{2} \Delta t C\right) U_{t+\Delta t}=\Delta t^{2} F_{n}-\left(\Delta t^{2} K-2 M\right) U_{t}-\left(M-\frac{\Delta t}{2} C\right) U_{t-\Delta t}
$$

Here, equation (9) can be converted to another form:

$$
M^{\prime} U_{t+\Delta t}=R_{t}^{\prime},
$$

where $M^{\prime}$ and $R_{t}^{\prime}$ are efficient mass matrix and load vector:

$$
\begin{aligned}
& M^{\prime}=\frac{1}{\Delta t^{2}} M+\frac{1}{2 \Delta t} C \\
& R_{t t}^{\prime}=F_{t}-\left(K-\frac{2}{\Delta t^{2}} M\right) U_{t}-\left(\frac{1}{\Delta t^{2}} M-\frac{1}{2 \Delta t} C\right) U_{t-\Delta t} .
\end{aligned}
$$

\section{Dynamic Simulation Analysis}

4.1. Influence of Driving Velocity. Because all kinds of load relate to time in explicit dynamic analysis, the inner surface of axle spline and outer surface of wheel spline are loaded by time-angular velocity array and time-moment array, respectively, as shown in Figures 7(a) and 7(b).

In order to illustrate the effect of angular velocity on spline couplings, this simplified spline coupling is loaded in three different ways. This loading process is divided into two phases which is acceleration stage and hold stage, as shown in Figure 7(a). According to the actual operating acceleration data of EMU trains, three representative accelerations $0.3 \mathrm{~m} /$ $\mathrm{s}^{2}, 0.5 \mathrm{~m} / \mathrm{s}^{2}$, and $1 \mathrm{~m} / \mathrm{s}^{2}$ are applied to the inner face of axle spline, respectively. At the final stage, the speed remains stable after reaching $0.11 \mathrm{rad} / \mathrm{s}$.

The resistance torque load is maintaining constant and applied to the outer surface of wheel spline. The starting time of torque loads are various since the initial instantaneous time is different, as shown in Figure 7(b).

Meanwhile, to increase the numerical efficiency and reduce the $\mathrm{CPU}$ time to an acceptable level, calculation time 


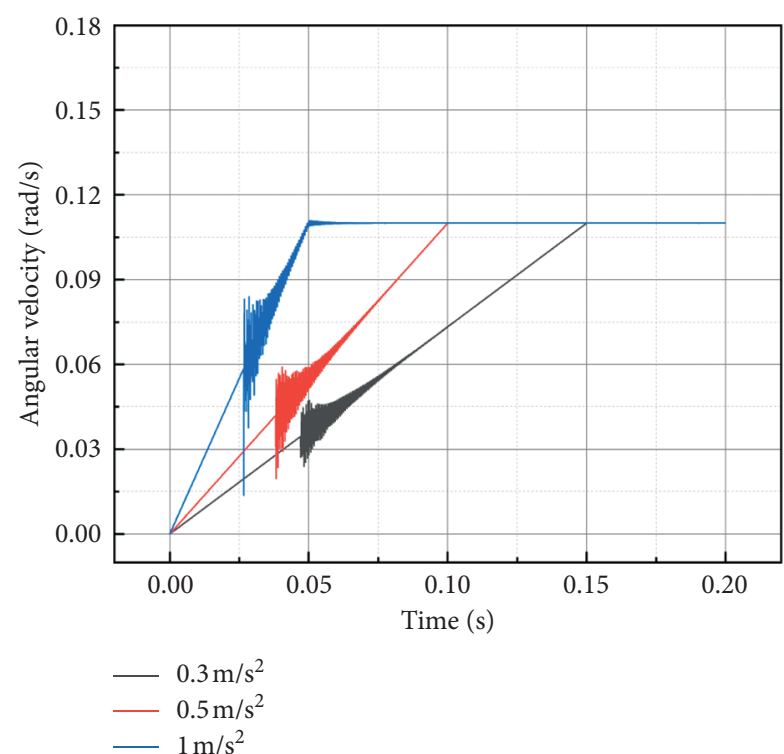

(a)

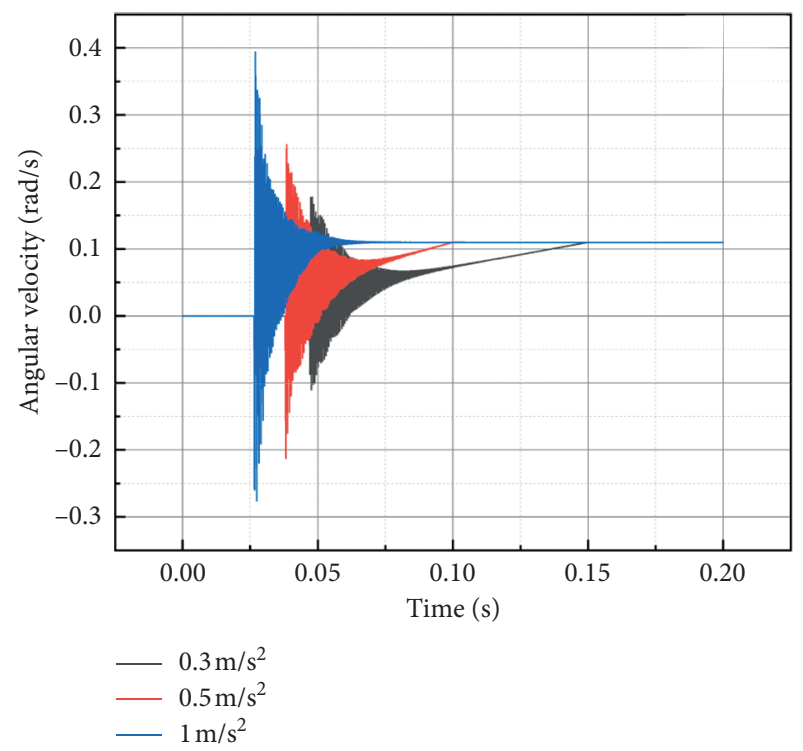

(b)

Figure 8: The comparison of angular velocity of axle and wheel spline under three loading cases. (a) The comparison of angular velocity of axle spline under three loading cases. (b) The comparison of angular velocity of wheel spline under three loading cases.

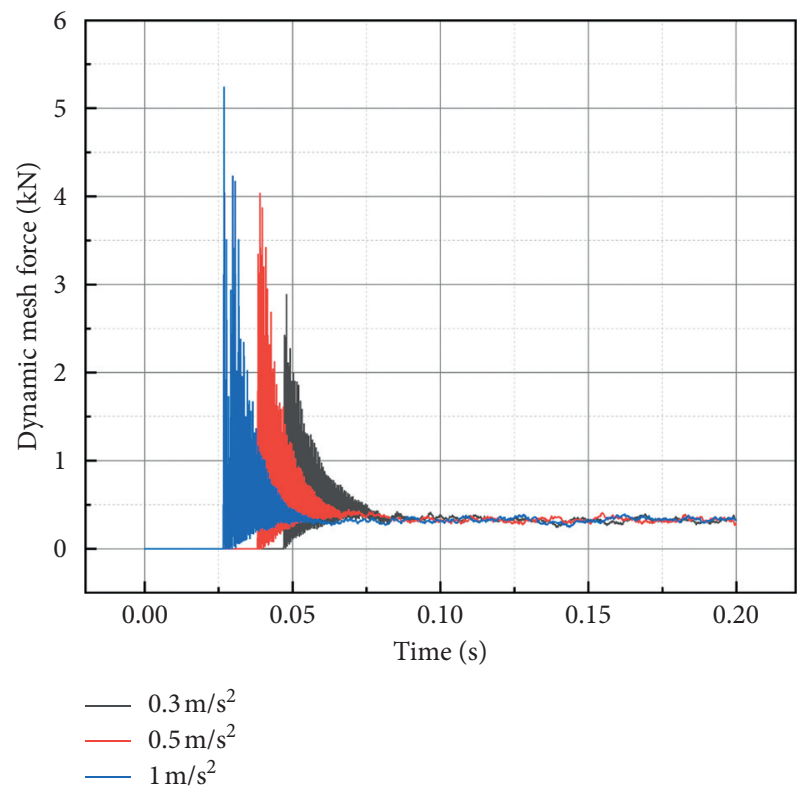

Figure 9: The comparison of meshing force of spline coupling under three loading cases.

is appropriately reduced to $0.2 \mathrm{~s}$ to ensure the calculation efficiency and accuracy.

Figures 8(a) and 8(b) show the dynamic response curve of angular velocity of axle spline and wheel spline under three combination loading cases. It is observed that higher driving speed leads to more significant fluctuation of angular velocity of spline coupling, while this phenomenon will gradually disappear with the procedure of speed synchronized of spline coupling. However, although the higher driving speed will lead to a negative impact on spline

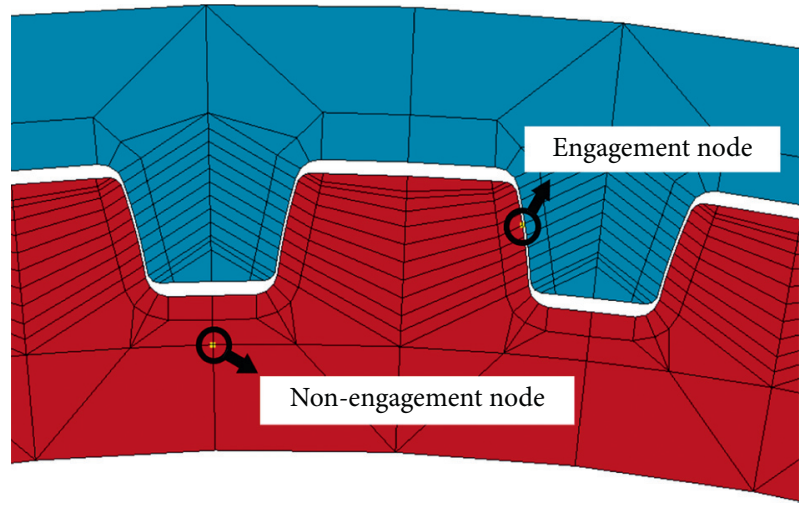

FIgURE 10: Typical contact node and noncontact node on axle spline.

coupling behavior, it promotes the speed synchronized process more quickly. For instance, as shown in Figure 8(b), the maximum speed fluctuation of wheel spline under three loading cases is $-0.3 \sim 0.4 \mathrm{rad} / \mathrm{s}, \quad-0.21 \sim 0.25 \mathrm{rad} / \mathrm{s}$, and $-0.12 \sim 0.17 \mathrm{rad} / \mathrm{s}$, respectively, while the corresponding fluctuation duration time is about $0.236 \mathrm{~s}, 0.042 \mathrm{~s}$, and $0.053 \mathrm{~s}$.

On the other hand, the speed fluctuation of wheel spline is obviously larger than that of axle spline during the initial contact period; this is mainly due to the huge difference in initial speed which results from the existing of resistance torque.

Meshing force of spline coupling can directly reflect the contact status and impact behavior because it always is generated and disappears with the contact and separation of axle and wheel spline. Figure 9 shows the real-time variation of the meshing force under three combination loading cases, from which it is clearly seen the variation of 

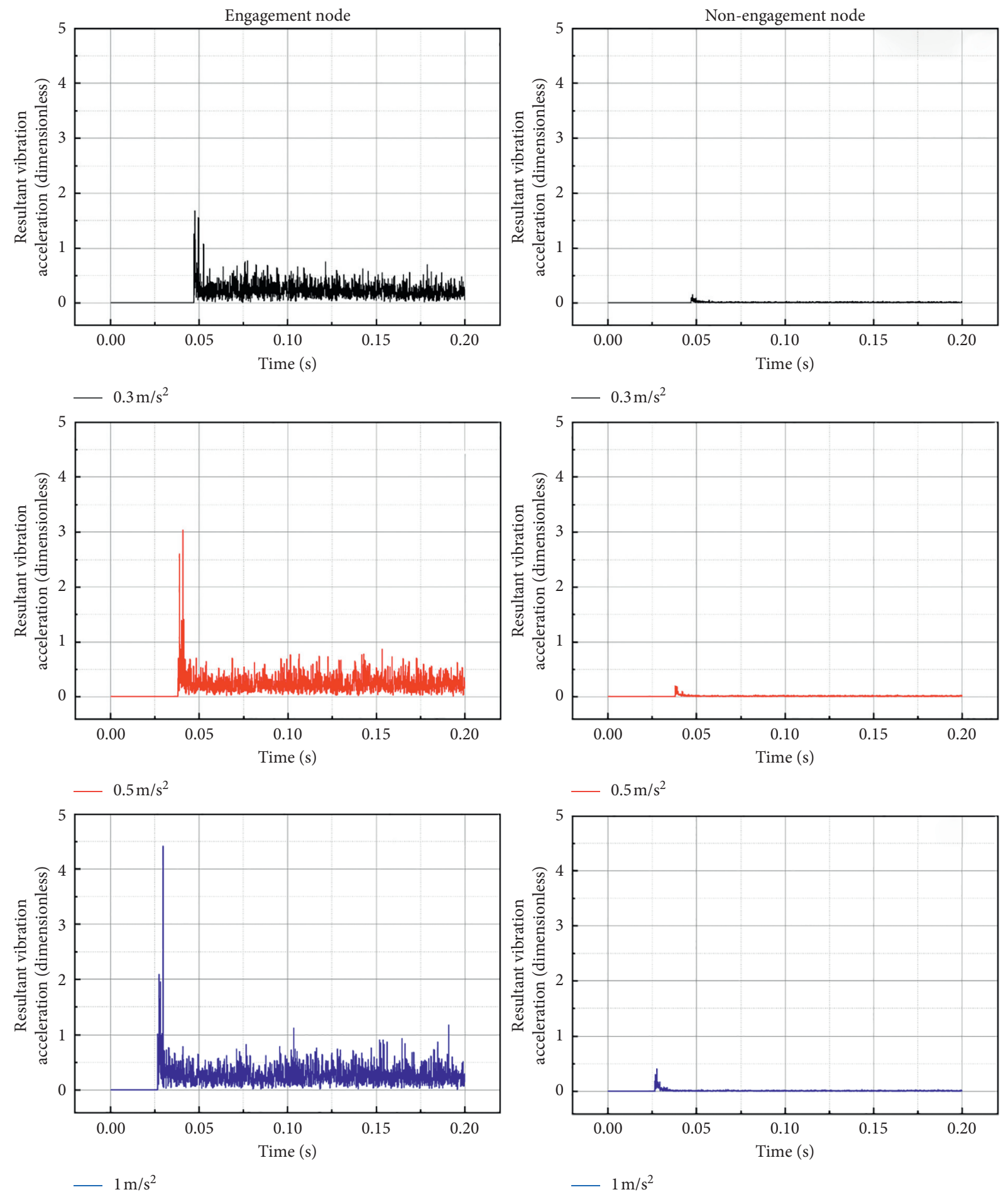

Figure 11: The comparison of resultant acceleration of two categories nodes on axle spline under three loading cases.

meshing force is divided into three phases. The first phase is empty travel of axle spline, during which the wheel spline remains static state until the instant before contact. The second phase has a severe and frequent impact behavior. Besides, it is noted that there is a positive correlation between instantaneous meshing force and engagement velocity. For instance, when the driving accelerations are $1 \mathrm{~m} / \mathrm{s}^{2}, 0.5 \mathrm{~m} / \mathrm{s}^{2}$, and $0.3 \mathrm{~m} / \mathrm{s}^{2}$, the corresponding maximum meshing forces are $5.23 \mathrm{kN}$, $4.03 \mathrm{kN}$, and $2.89 \mathrm{kN}$, respectively. The third phase shows that meshing force gradually decline to a constant value, about $300 \mathrm{~N} \sim 320 \mathrm{~N}$, which shows the case of spline coupling has reached a relatively stable stage. This result also implies that as long as the engagement velocity in final stage remains the same, the meshing force will fluctuate within a roughly same range. 


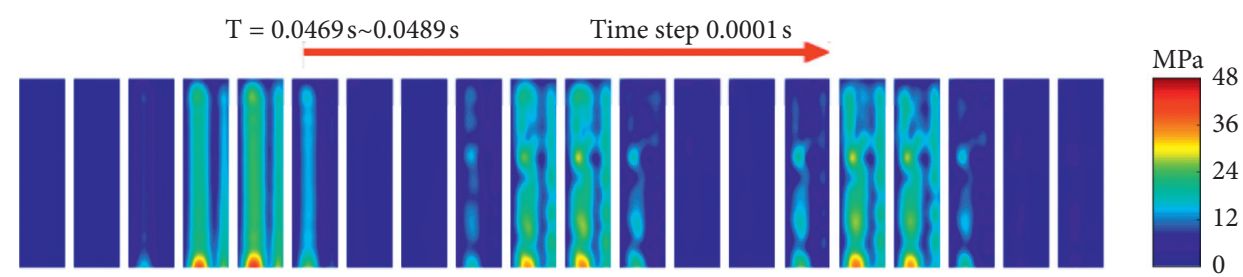

(a)

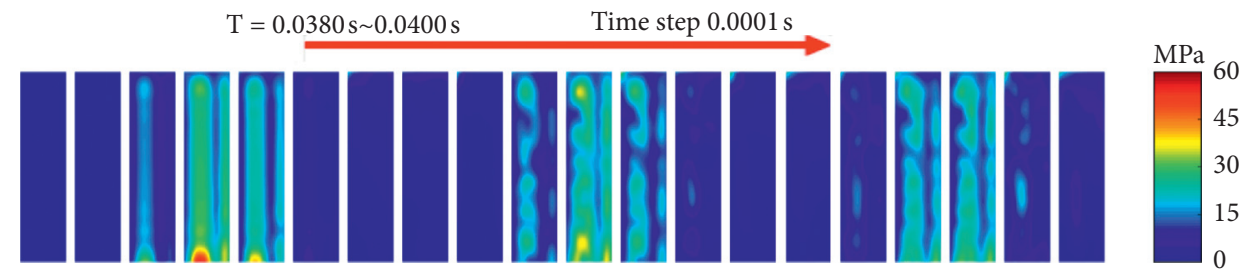

(b)

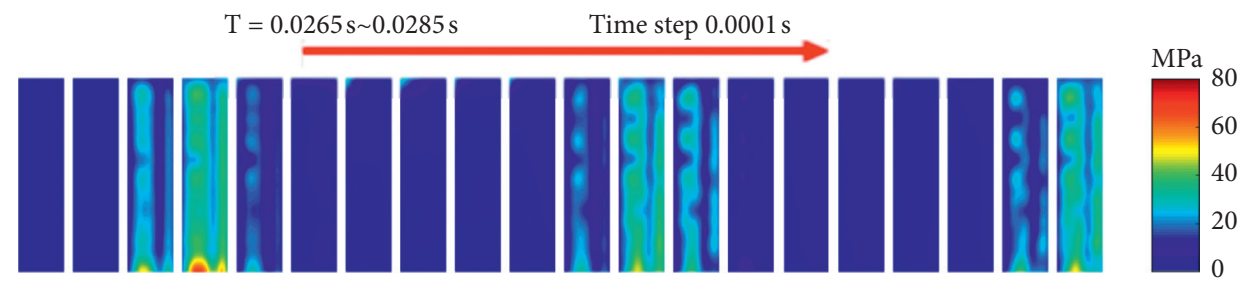

(c)

Figure 12: Phase I: Real-time stress distribution of the contact area on axle spline surface under different loading cases. (a) Real-time stress status under $0.3 \mathrm{~m} / \mathrm{s} 2$ driving rate, \#10 tooth. (b) Real-time stress status under $0.5 \mathrm{~m} / \mathrm{s} 2$ driving rate, \#10 tooth. (c) Real-time stress status under $1 \mathrm{~m} / \mathrm{s} 2$ driving rate, \#10 tooth.

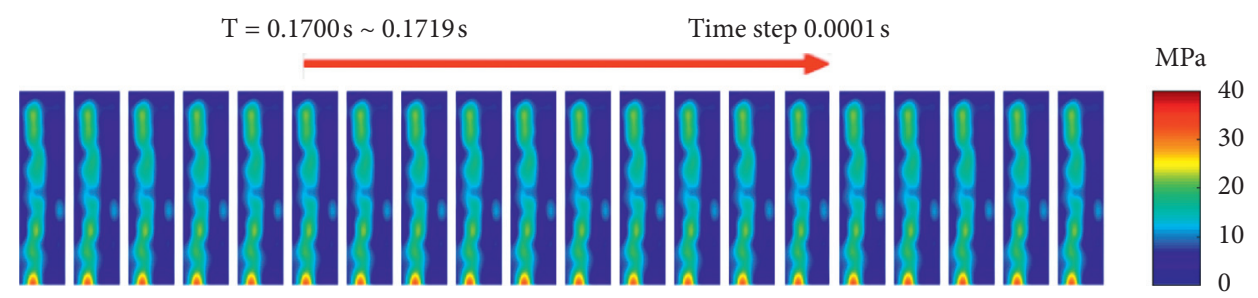

(a)

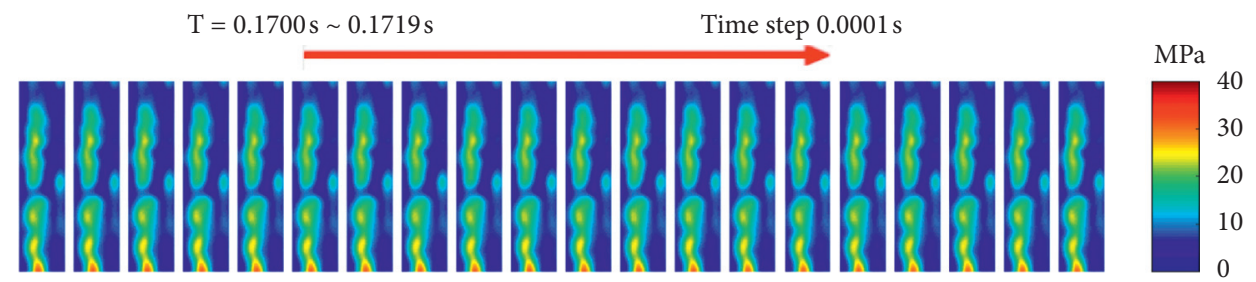

(b)

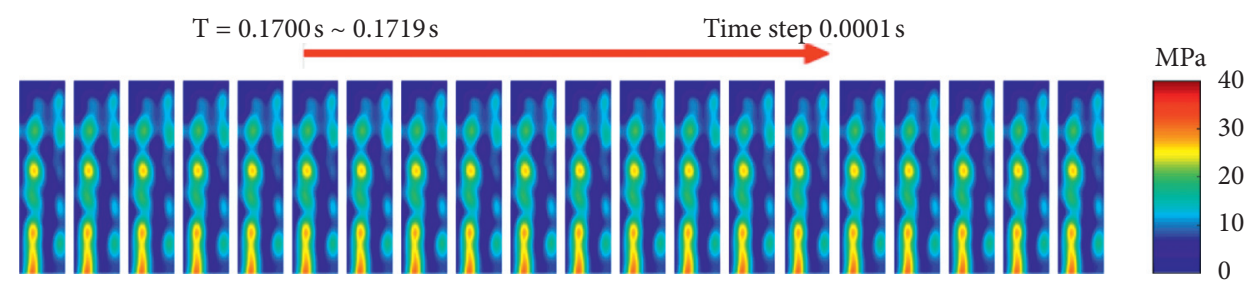

(c)

FIgURe 13: Phase II: Real-time stress distribution of the contact area on axle spline surface under different loading cases. (a) Real-time stress status under $0.3 \mathrm{~m} / \mathrm{s} 2$ driving rate, \#10 tooth. (b) Real-time stress status under $0.5 \mathrm{~m} / \mathrm{s} 2$ driving rate, \#10 tooth. (c) Real-time stress status under $1 \mathrm{~m} / \mathrm{s} 2$ driving rate, \#10 tooth. 

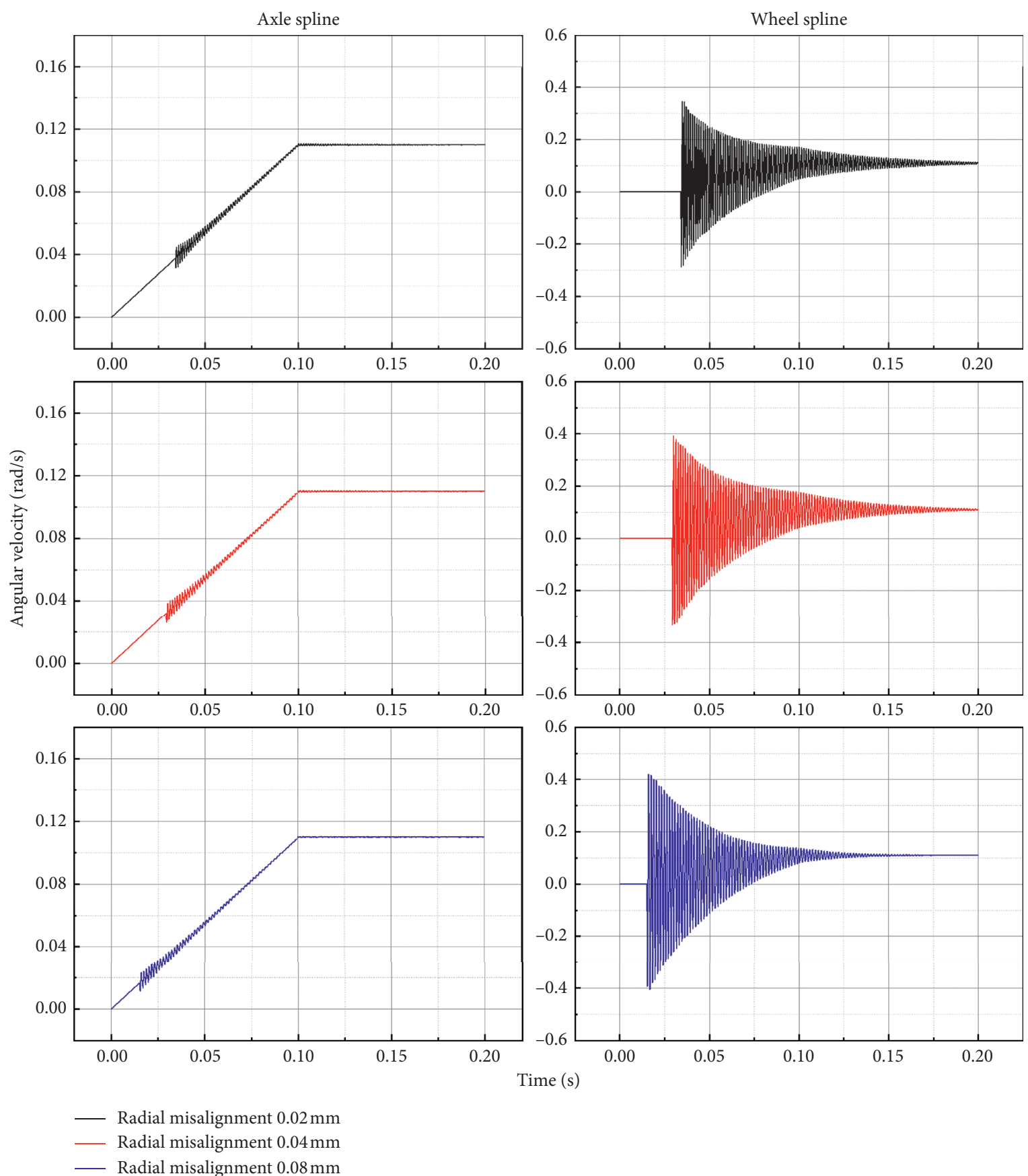

— Radial misalignment $0.04 \mathrm{~mm}$

Radial misalignment $0.08 \mathrm{~mm}$

FIgURE 14: The comparison of angular velocity of spline coupling with different radial misalignments, $\delta$, under identical loading case.

In order to investigate the effect of vibration acceleration on the process of spline engagement, two representative nodes were selected on the axle spline as shown in Figure 10. Here, the vibration signals of engagement node and nonengagement node reflect the vibration severity of contact and noncontact area, respectively. The resultant vibration accelerations of typical nodes are shown in Figure 11 for the above three loading cases. Two main observations can be made from this figure. First of all, at the identical driving rate, the vibration acceleration amplitude of engagement node is much larger than that of the nonengagement node. Secondly, the maximum amplitude of vibration for the engagement node in the contact area is $1.68,3.03$, and 4.42 , respectively, which indicates that an increase in engagement velocity would only induce higher vibration response, not affecting the patterns of vibration signal significantly.

According to the previous research literature conducted by Hong et al [12-14], as the pure torque increases, the contact area gradually moves towards the edge of the spline teeth along the profile direction, while the stress distribution pattern remains the same. This indicates that analysis of the stress state of any pair of tooth surface can reflect the overall stress characteristics of spline couplings. As stated earlier and shown graphically in Figure 4(b), in order to obtain the 

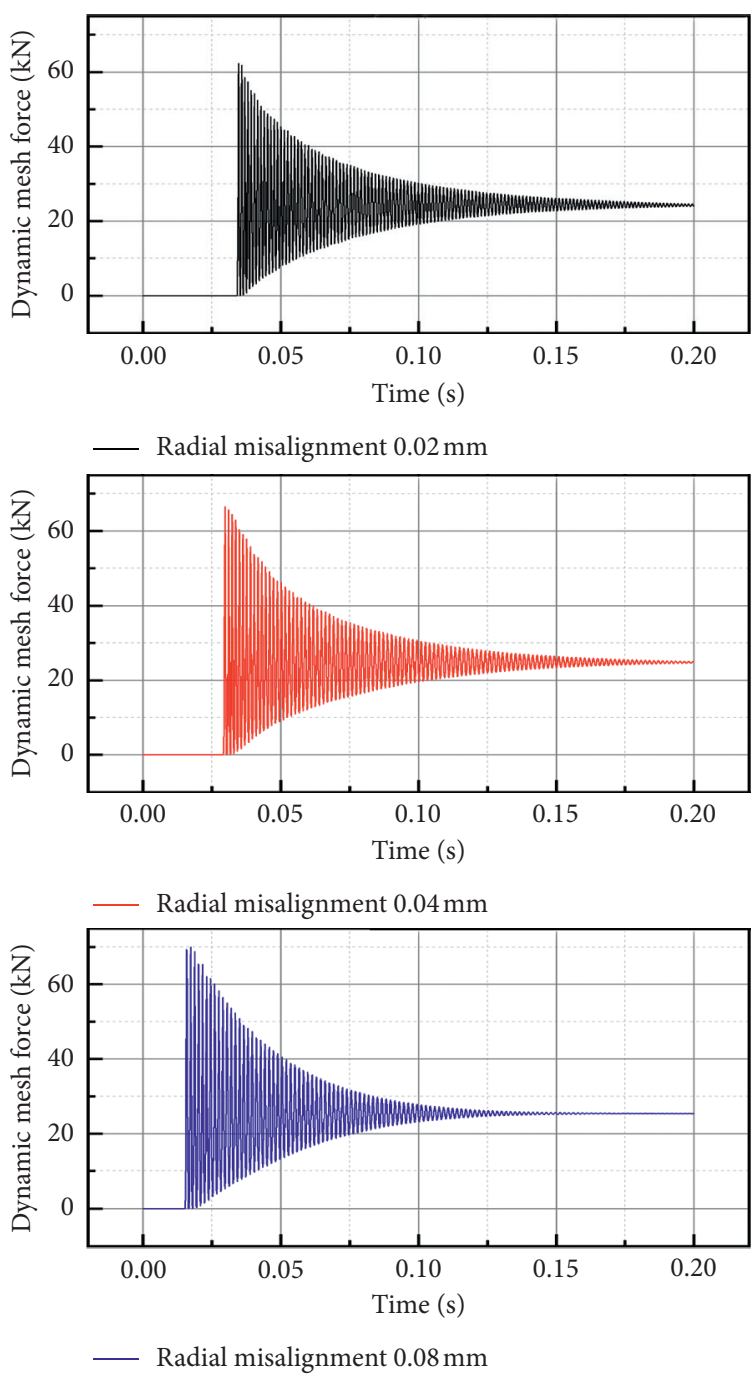

FIGURE 15: The comparison of meshing force of spline coupling with different radial misalignments $\delta$ under identical loading case.

stress status of spline interfaces in real-time, \#10 tooth was chosen to analyze.

Figure 12 shows the maximum contact stress of 10 th tooth on the axle spline over the initial contact phase (Phase I) under different loading cases, from which it is predicted that the spline engagement is a repeated process of "contactseparate-contact," and there is a positive correlation between dynamic contact stress and engagement velocity. In addition, it is also noted that with increase of driving velocity, the engagement efficiency decreases dramatically and vice versa. For instance, the maximum contact stress is about $44.7 \mathrm{MPa}$, 56.7 MPa, and 72.7 MPa for driving velocity $0.3 \mathrm{~m} / \mathrm{s}^{2}, 0.5 \mathrm{~m} /$ $\mathrm{s}^{2}$, and $1 \mathrm{~m} / \mathrm{s}^{2}$, respectively, and the two adjacent contact times under this condition are $0.0002 \mathrm{~s}, 0.0004 \mathrm{~s}$, and $0.0005 \mathrm{~s}$, respectively. This result illustrates the fact that the higher driving velocity will introduce a severe vibration at the early stage of engagement, resulting in the instantaneous rotating velocity of spline coupling not being synchronized, which not only causes a sudden stress change on the surface of the tooth, but also leads to rapid separation of meshing surface.

In comparison with Figure 12 for the dynamic stress responses of \#10 tooth in axle spline at the initial contact phase, Figure 13 shows the real-time equivalent stress of the same tooth at the constant velocity phase (Phase II) under different loading cases. The maximum contact stress declines dramatically to $36.5 \mathrm{MPa}, 37.2 \mathrm{MPa}$, and $38.2 \mathrm{MPa}$ over Phase II with an identical time interval. It is observed that the stress distribution patterns remain approximately the same and there is no obvious difference in peak value of contact stress. Here, the maximum contact stress is reduced by more than $47 \%$, which can be explained by the fact that the impact behavior resulting from the engagement process of spline has a negative effect on the stress state of the tooth surface, and the higher engagement velocity will induce a more obvious stress response in an extremely short time interval. Moreover, the fatigue tests conducted by F. Curà et al.[24] showed that the most significant surface damages 

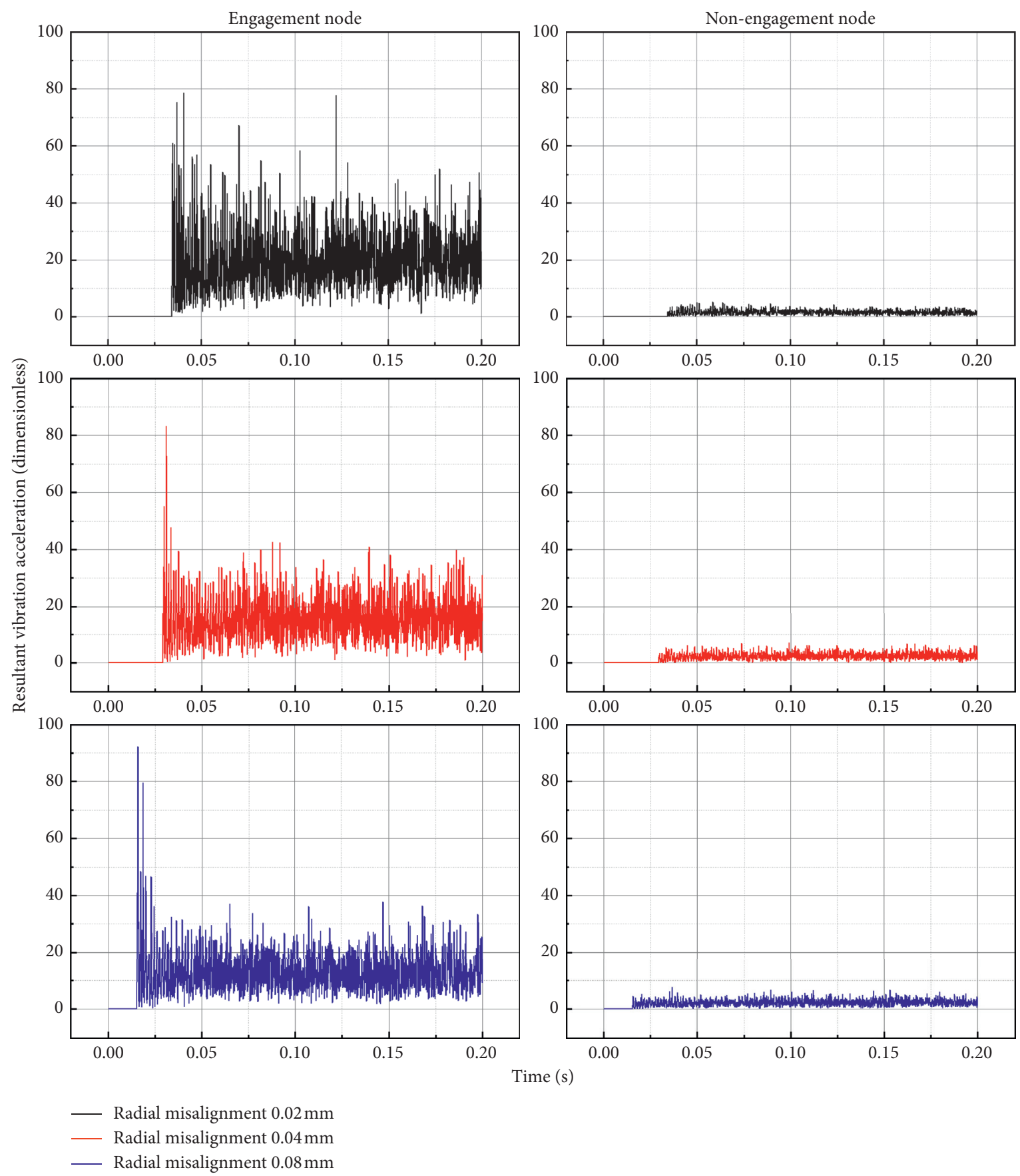

— Radial misalignment $0.04 \mathrm{~mm}$

— Radial misalignment $0.08 \mathrm{~mm}$

FIgURE 16: The comparison of resultant vibration of two categories nodes on axle spline with different radial misalignments $\delta$ under the identical loading case.

were at the edge of the spline teeth along the profile direction, which helps to understand the stress distribution in Figures 12 and 13.

4.2. Effect of Assemble Variations on the Nominal System. The investigation of spline dynamic characteristics discussed all assumed perfect assemble conditions above, ignoring the effect of misalignments, which introduces a slight difference in tooth clearance. In general, the misalignment of spline couplings has been recognized as harmful to splines because it introduces significant stress concentration on spline teeth and accelerates wear and fretting fatigue of splines [25-27].

4.3. Radial Misalignment. Figure 14 shows the dynamic response curve of angular velocity of axle spline and wheel spline with different radial misalignments, $\delta=0.02 \mathrm{~mm}$, $0.04 \mathrm{~mm}$, and $0.08 \mathrm{~mm}$, under a normal loading case (mentioned before). It is observed that a more severe radial 


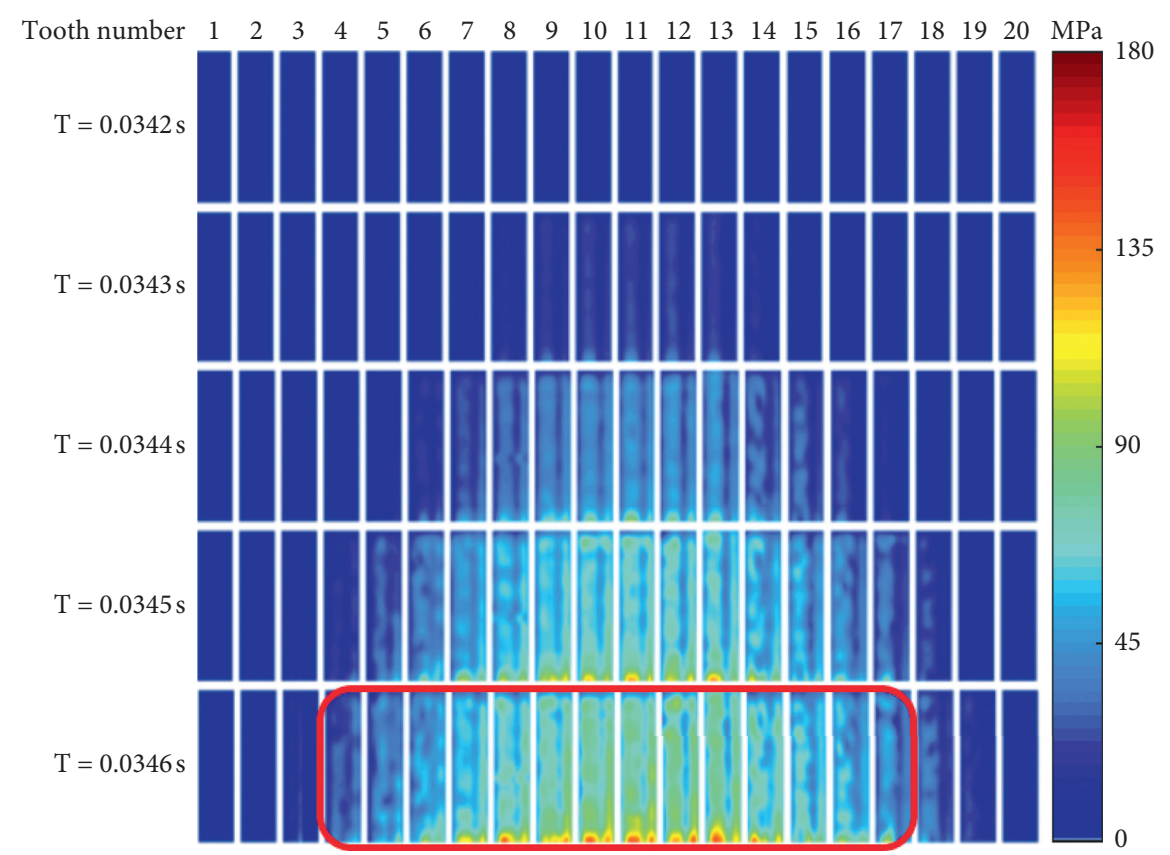

FIGURE 17: Real-time stress distribution of the contact area on axle spline surface under the identical loading case, at $\delta=0.02 \mathrm{~mm}$.

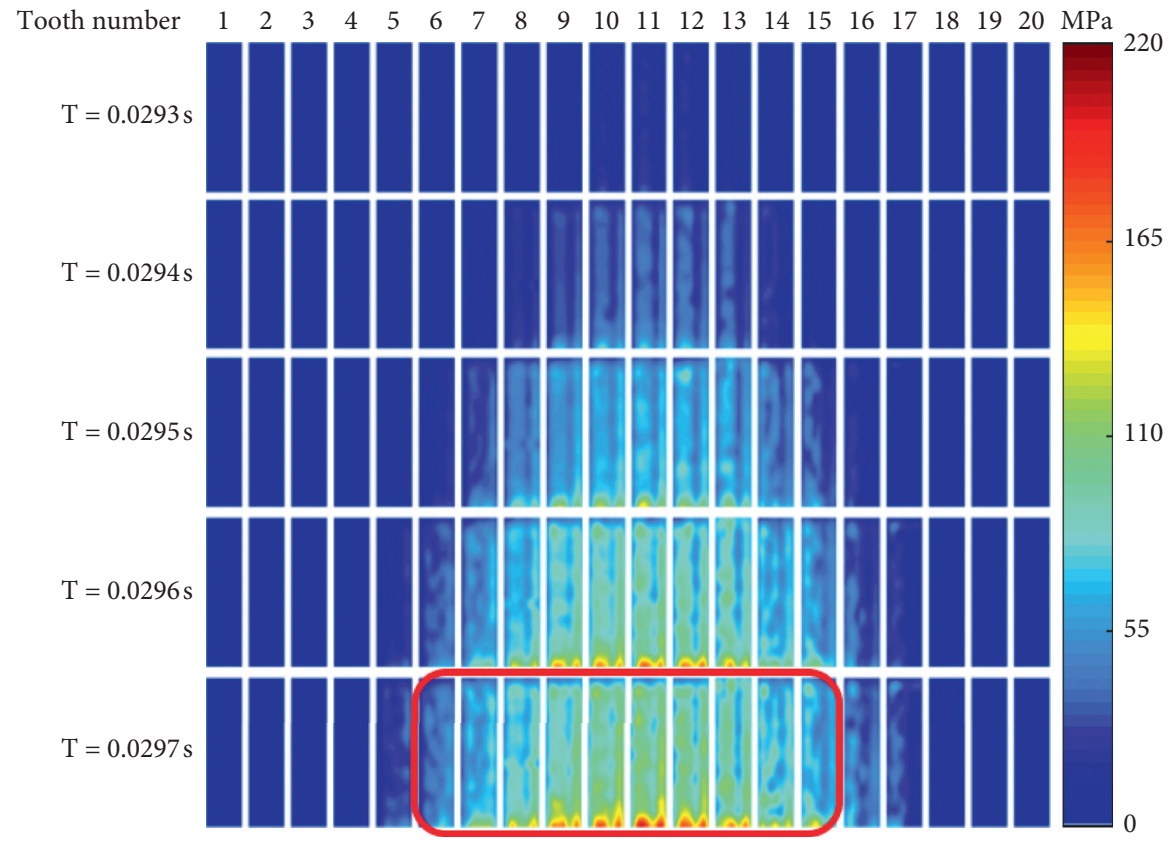

FIGURE 18: Real-time stress distribution of the contact area on axle spline surface under the identical loading case, at $\delta=0.04 \mathrm{~mm}$.

misalignment will shorten the empty travel of axle spline and accelerate the engagement process, while also leading to a more obvious rotating speed fluctuation phenomenon.

Figure 15 shows the real-time variation of meshing force with different radial misalignments, $\delta=0.02 \mathrm{~mm}, 0.04 \mathrm{~mm}$, and $0.08 \mathrm{~mm}$, at the same loading condition. Unlike in the ideal assemble situation, the dynamic mesh force has a significant increase with the presence of radial misalignment, the maximum meshing force increases dramatically to $62.3 \mathrm{kN}, 66.5 \mathrm{kN}$, and $70.0 \mathrm{kN}$ for radial misalignment $\delta=0.02 \mathrm{~mm}, 0.04 \mathrm{~mm}$, and $0.08 \mathrm{~mm}$, respectively. However, this value is only $4.03 \mathrm{kN}$ for exactly identical tooth clearance under the same loading condition. This occurs because the intentional radial misalignment alters the tooth clearance for whole spline coupling, and a portion of clearance is much smaller than others, which will significantly reduce the number of teeth involved in the meshing process and leads to a substantial increase in the meshing force. Besides, it is also noted that with various radial misalignments, not only the the impact periods are extended, but also a relatively 


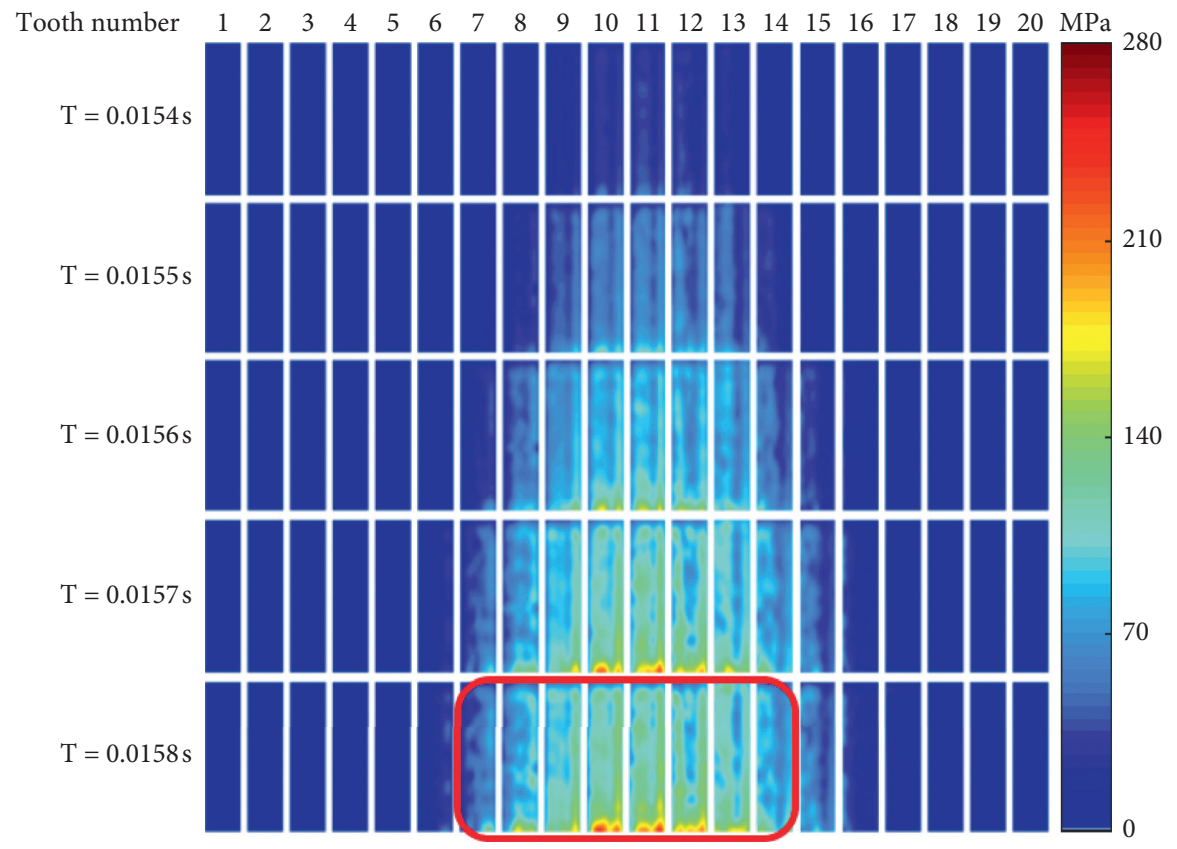

Figure 19: Real-time stress distribution of the contact area on axle spline surface under the identical loading case, at $\delta=0.08 \mathrm{~mm}$.

higher level of meshing force is maintained after reaching a stable phase.

Figure 16 shows the resultant vibration acceleration of two typical nodes (shown in Figure 10) with different radial misalignments, $\delta=0.02 \mathrm{~mm}, 0.04 \mathrm{~mm}$, and $0.08 \mathrm{~mm}$, at the same loading condition. In comparison with Figure 11, with perfect assemble situation, the amplitudes of vibration acceleration for both selected nodes have increased significantly, while the frequency of vibration acceleration also exhibits a rapidly increasing trend. For instance, when radial misalignment is $0.08 \mathrm{~mm}$, the maximum amplitude of vibration acceleration is 92.2 for engagement node and 2.3 for non-engagement node, while this value is 3.03 and 0.02 for perfect assemble situation under same loading condition. This result illustrates that radial misalignment has a negative influence on the engagement of spline coupling because high-frequency vibration would accumulate damage on the tooth interface, resulting in fatigue failure of spline teeth.

In order to efficiently and accurately explain the effect of radial misalignment on the real-time stress distribution of teeth interface, the teeth that fully or partially participate in the engagement process are selected to analyze, while ignoring the teeth that far away from contact. Figures 17-19 show the real-time stress status matrix of splines with various radial misalignments $\delta=0.02 \mathrm{~mm}, 0.04 \mathrm{~mm}$, and $0.08 \mathrm{~mm}$ at the same loading condition.

As discussed before, radial misalignments mess up all the clearance of spline coupling, where the spline engagement process will exhibit the following behaviors; that is, only a portion of teeth participate in the engagement and the time for these teeth to enter the engagement is also different. In addition, radial misalignment also has a dominant effect on stress distribution. For instance, for a given loading condition and identical teeth, with an increase in radial misalignment, there is a remarkable difference (Figures 17-19) that at the last phase, the number of teeth involved in engagement gradually decreases from 14 to 11 and 8, while these numbers accounts for about $29 \%, 21 \%$, and $17 \%$ of all axle spline teeth. Meanwhile, for a certain radial misalignment like $\delta=0.08 \mathrm{~mm}$, it is noted that the load sharing on each tooth is not uniform, where teeth \#10-12 have stress concentration phenomenon and experience a higher load, teeth \#6-9 and \#13-15 have lower dynamic stress response and only share a small portion of the load. Besides, the maximum dynamic stress is $174.8 \mathrm{MPa}, 215.6 \mathrm{MPa}$, and $276.0 \mathrm{MPa}$ for radial misalignment $\delta=0.02 \mathrm{~mm}, 0.04 \mathrm{~mm}$, and $0.08 \mathrm{~mm}$, respectively, which is almost 3 5 times of $56.7 \mathrm{MPa}$ under perfect assemble situation. Further, the results mentioned above have a good agreement with the conclusions proposed by Guo et al.[28], which illustrated the influence of misalignment on the tooth-load distribution.

4.4. Circumferential Misalignment. Figure 20 shows the dynamic response curve of angular velocity of axle spline and wheel spline with different circumferential misalignments, $\varphi=0.01^{\circ}, 0.02^{\circ}$, and $0.04^{\circ}$, under a normal loading case (mentioned before). In comparison with Figure 8, for the identical loading case with the ideal assemble situation, the speed fluctuation pattern approximately remains the same, and a remarkable difference is that with an increase in circumferential misalignment, the instantaneous amplitude of speed fluctuation increases as well.

Figure 21 shows the real-time variation of meshing force with different circumferential misalignments, $\varphi=0.01^{\circ}$, $0.02^{\circ}$, and $0.04^{\circ}$, at the same loading condition. It is observed that the initial contact time is delayed with the increase of circumferential misalignment. And the peak value of 

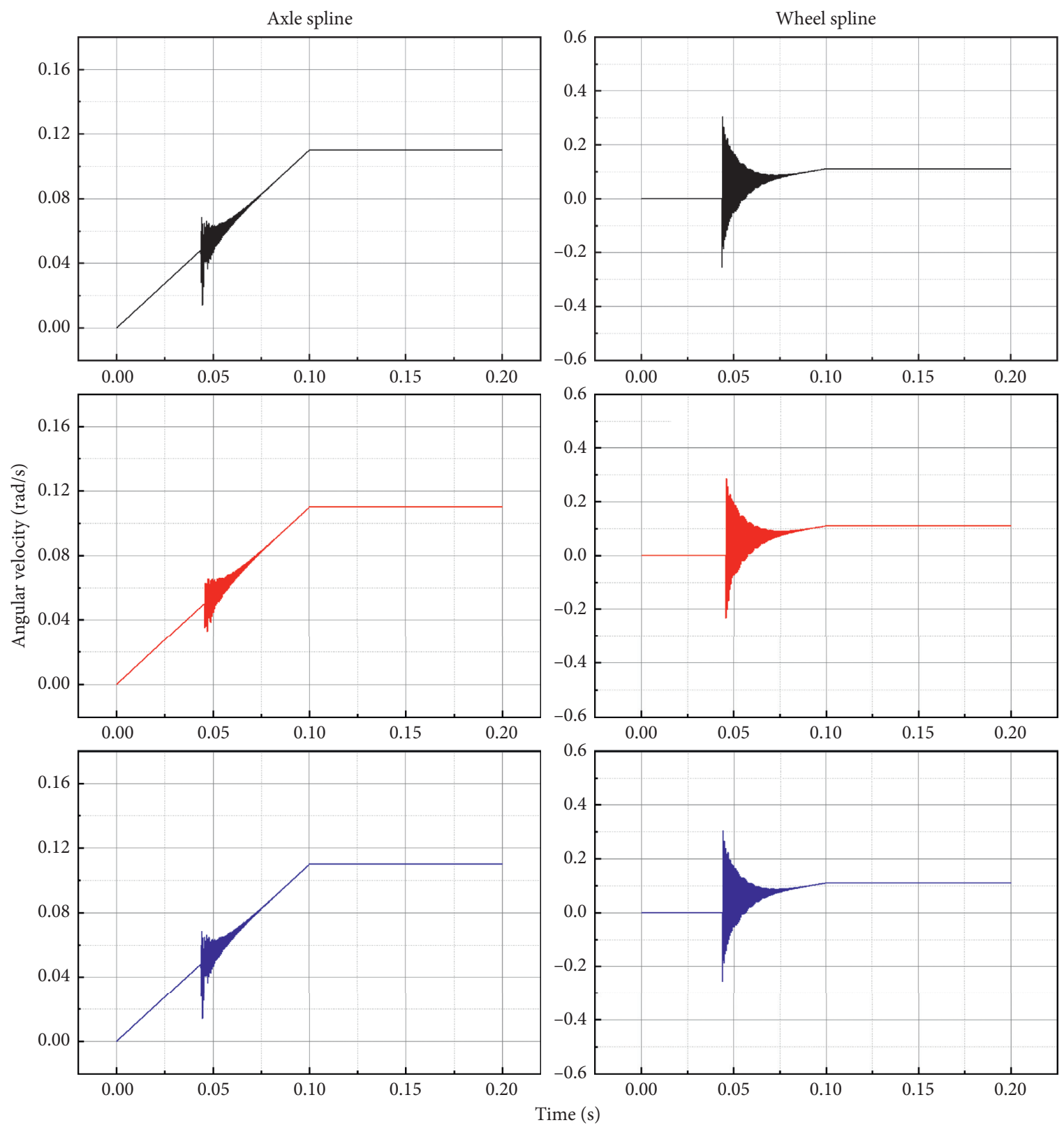

- Circumferential misalignment $0.01^{\circ}$

— Circumferential misalignment $0.02^{\circ}$

- Circumferential misalignment $0.04^{\circ}$

FIGURE 20: The comparison of angular velocity of spline coupling with different circumferential misalignments $\varphi$ under identical loading case.

meshing force, similar to that in Figure 9, has a slight increase trend, reaching $4.25 \mathrm{kN}, 4.54 \mathrm{kN}$, and $4.72 \mathrm{kN}$ for circumferential misalignment, $\varphi=0.01^{\circ}, 0.02^{\circ}$, and $0.04^{\circ}$. This can be explained by the fact that the circumferential misalignment helps expand the clearance for all teeth, which extends the empty period of axle spline and results in a higher engagement speed. This process will postpone the initial contact time and excite a stronger response of meshing force. Moreover, it is also noted that the circumferential misalignment has little effect on the mesh force in the stable engagement stage, maintaining the same level with Figure 9.

Figure 22 shows the resultant vibration acceleration of two typical nodes (shown in Figure 10) with circumferential misalignment $\varphi=0.01^{\circ}, 0.02^{\circ}$, and $0.04^{\circ}$ at the same loading condition. The maximum value of vibration acceleration is $4.51,4.62$, and 5.47 , respectively. As a reference, this value is 3.03 in Figure 11. Besides, the distribution of these signals also indicates that the circumferential misalignment would only enlarge the amplitude of instantaneous impact while 


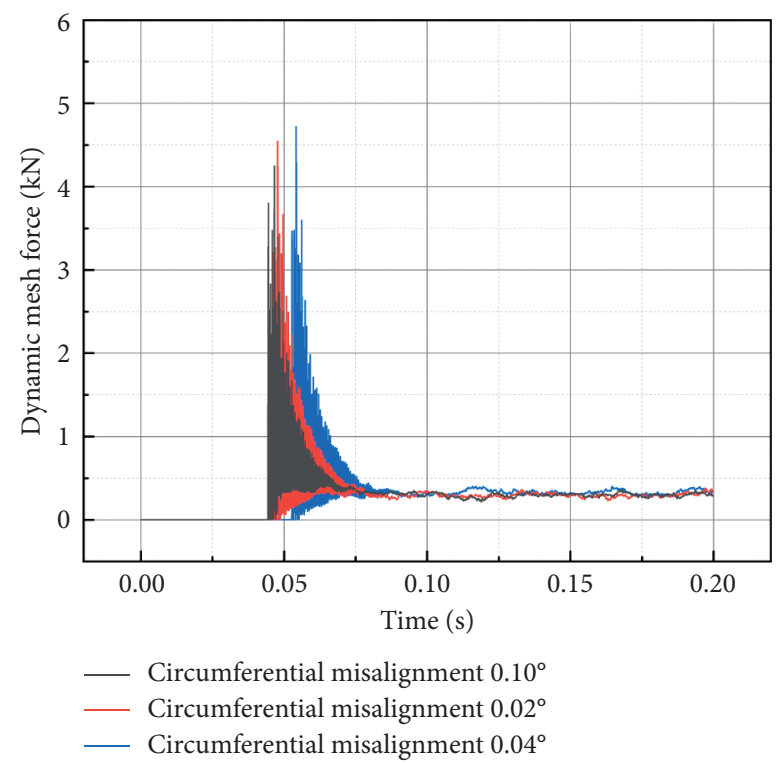

FIGURE 21: The comparison of meshing force of spline coupling with different circumferential misalignments $\varphi$ under identical loading case.

not affecting the engagement method and sequence of spline teeth.

As illustrated and discussed earlier in Figures 12 and 13, \#10 tooth is selected again to analyze and make a comparison with previous results. Figures 23 and 24 show the real-time contact stress of the same tooth on the axle spline over the initial contact phase (Phase I) and constant velocity driving phase (Phase II) under the same loading condition, respectively. Again, the conclusion obtained from previous analysis verified, such as a time lag for initial contact and instantaneous impact phenomenon. Further, it is observed that for Phase I, the maximum amplitude of dynamic stress increases due to the presence of circumferential misalignment, along with the rapid alternation of stress status on the tooth surface, and this situation will reduce the load bearing capacity of the spline and result in fatigue failure. As for Phase II, the various circumferential misalignments have little effect on the stress value and distribution, maintaining the same pattern with that in the nominal system.

\section{Results and Discussion}

In this study, a finite-element-based simplified computational model of a wheel-axle spline under dynamic loading cases is proposed. The dynamic behavior of the wheel-axle spline coupling with identical tooth clearance under different loading rates is characterized. It is observed that an increase of loading rate in Phase I would dramatically induce a higher dynamic response of engaged teeth, such as significant rotating speed fluctuation, rapid increase of vibration acceleration, and mesh force. Moreover, the realtime stress status of a certain tooth on axle-spline revealed that the spline engagement is a rapidly repeated process of "contact-separate-contact," while the loading rate has a dominant effect on the instantaneous stress value.

Besides, during the period of normal loading rate (Phase II), the dynamic response and real-time stress status maintain approximately the same with identical loading rate and exhibit a remarkable difference with previous results. The comparison illustrated that the obvious vibration behavior and stress response mainly occurred at the beginning of spline engagement. However, once this process reached stable, these parameters would maintain a relatively lower level.

An extensive parameter study on typical variations of the nominal system was performed. Here, the misalignment of spline coupling was classified into radial misalignment and circumferential misalignment in terms of assembling error. Compared to the idea assemble case, spline tooth pairs that have misalignment tend to experience higher vibration and impact over a local contact area, thus sharing more load. For the radial misalignment case, significant stress concentration phenomenon was observed in some teeth surface and the load sharing of each tooth on axle spline was extremely unbalanced. And as for the circumferential misalignment 


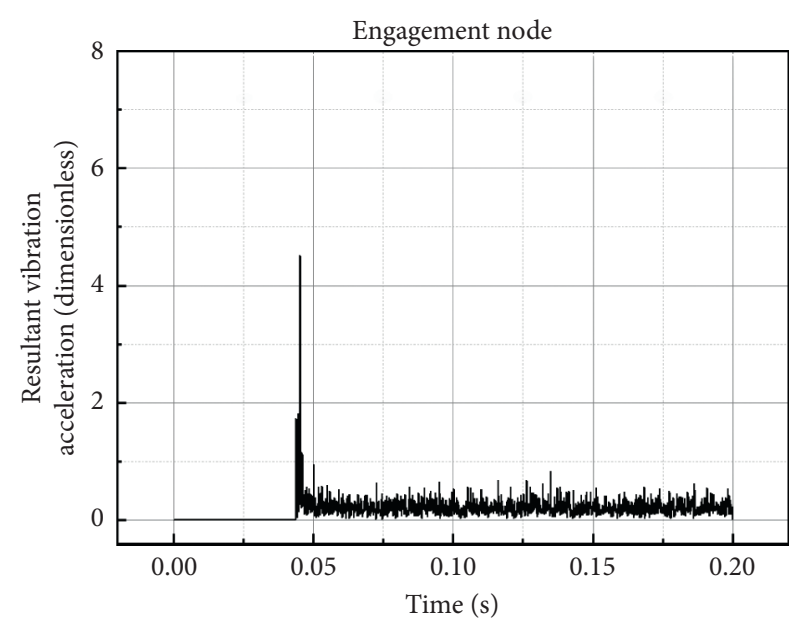

— Circumferential misalignment $0.01^{\circ}$

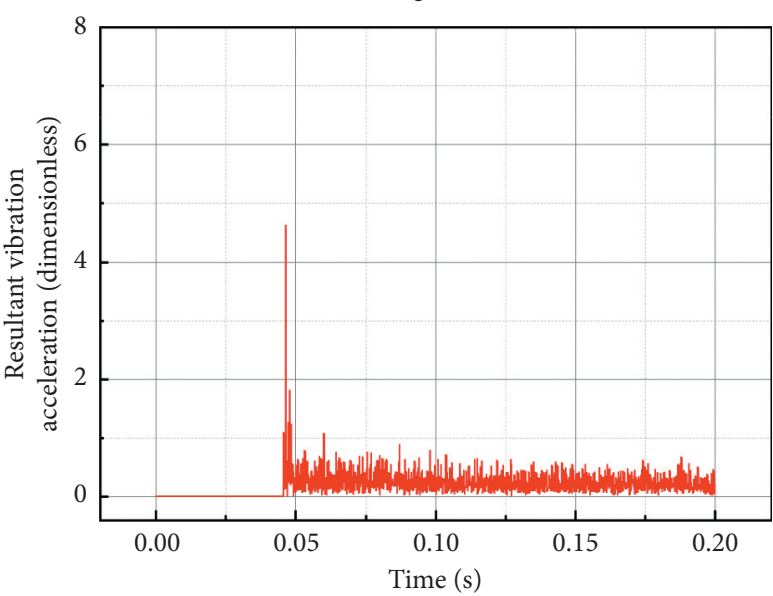

- Circumferential misalignment $0.02^{\circ}$

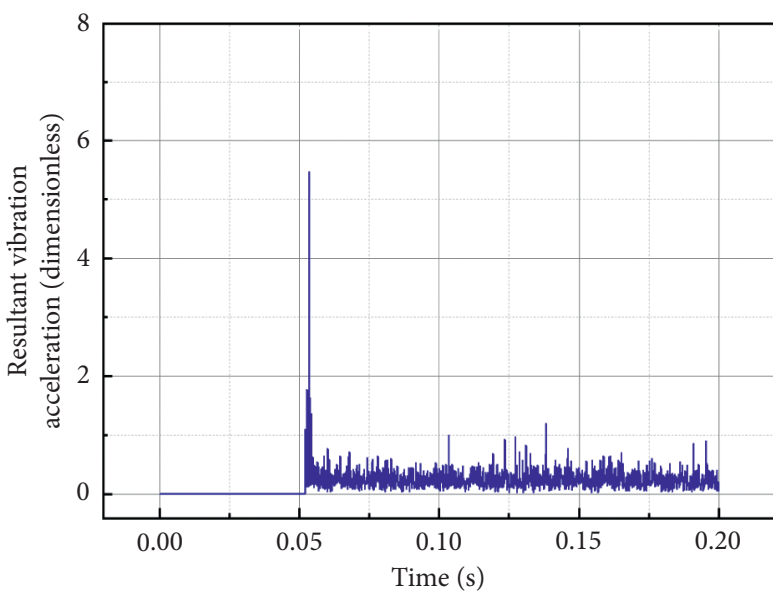

— Circumferential misalignment $0.04^{\circ}$

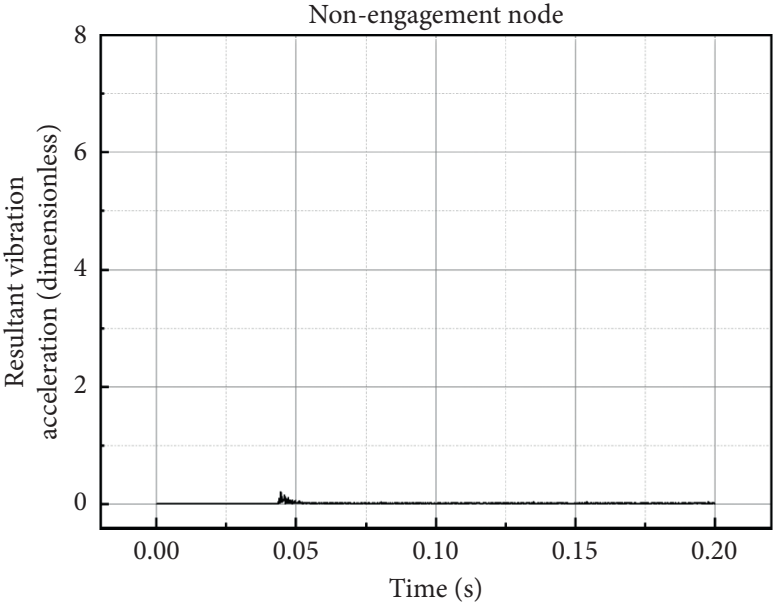

— Circumferential misalignment $0.01^{\circ}$

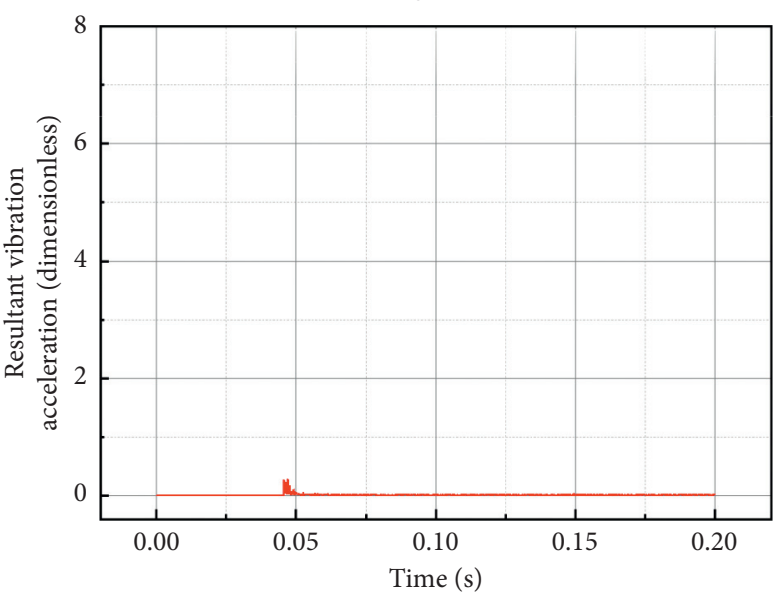

- Circumferential misalignment $0.02^{\circ}$

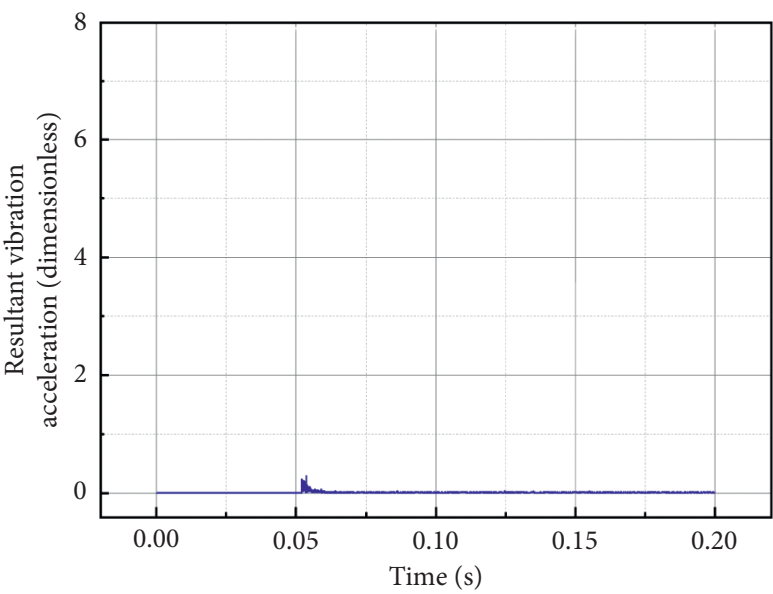

- Circumferential misalignment $0.04^{\circ}$

FIGURE 22: The comparison of resultant vibration of two categories nodes on axle spline with different circumferential misalignments $\varphi$ under identical loading case. 


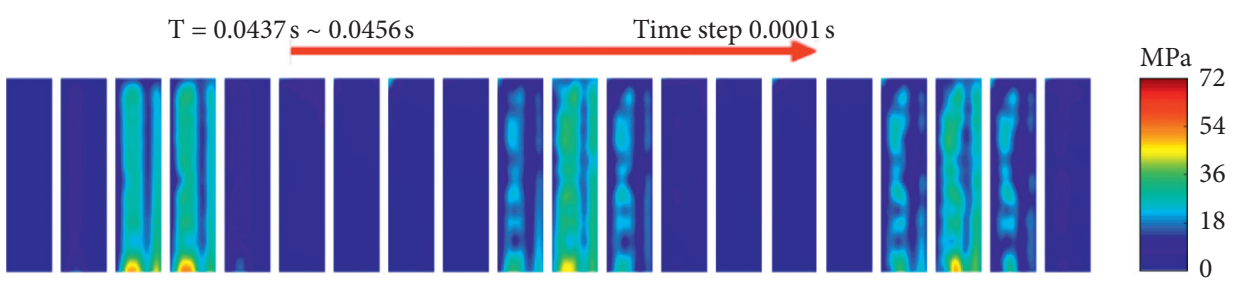

(a)

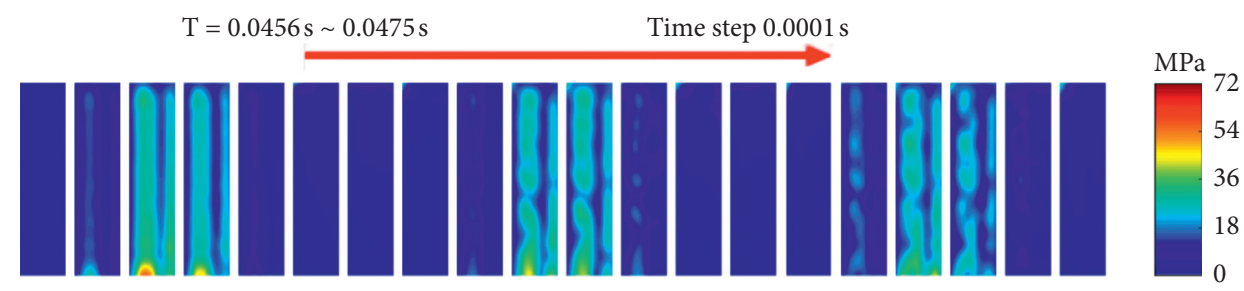

(b)

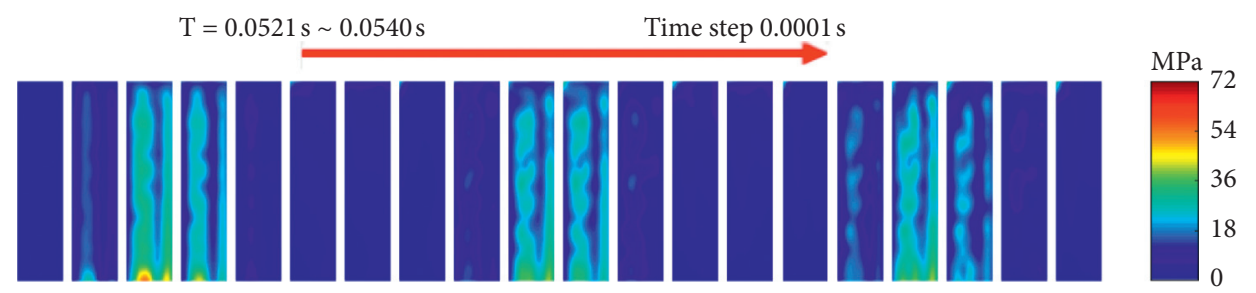

(c)

Figure 23: Phase I: Real-time stress distribution of the contact area on axle spline surface under identical loading case, at $\varphi=0.01^{\circ}, 0.02^{\circ}$, and $0.04^{\circ}$. (a) Real-time stress status with circumferential misalignment $\varphi=0.01^{\circ}$ under $0.5 \mathrm{~m} / \mathrm{s} 2$ driving rate, \#10 tooth. (b) Real-time stress status with circumferential misalignment $\varphi=0.02^{\circ}$ under $0.5 \mathrm{~m} / \mathrm{s} 2$ driving rate, \#10 tooth. (c) Real-time stress status with circumferential misalignment $\varphi=0.04^{\circ}$ under $0.5 \mathrm{~m} / \mathrm{s} 2$ driving rate, \#10 tooth.

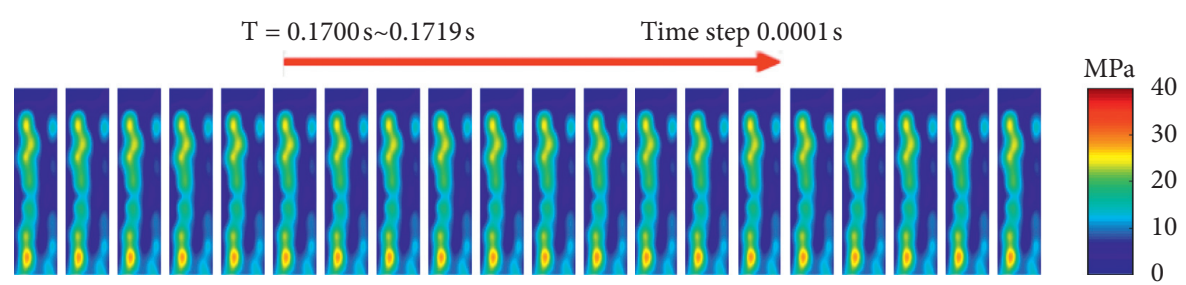

(a)

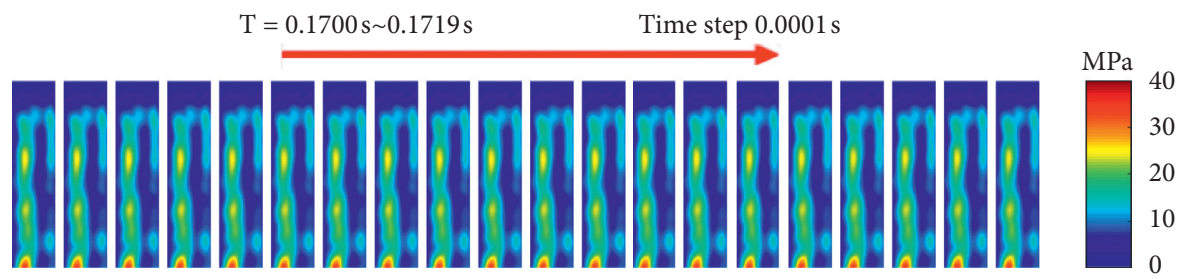

(b)

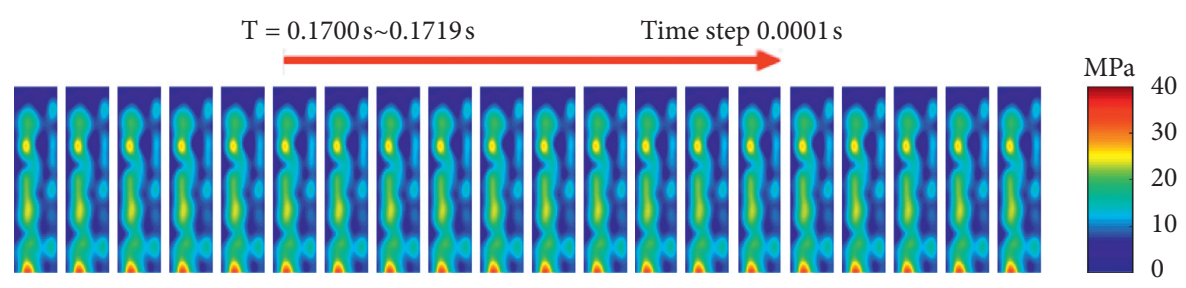

(c)

FIGURE 24: Phase II: Real-time stress distribution of the contact area on axle spline surface under identical loading case, at $\varphi=0.01^{\circ}, 0.02^{\circ}$ and $0.04^{\circ}$. (a) Real-time stress status with circumferential misalignment $\varphi=0.01^{\circ}$ under $0.5 \mathrm{~m} / \mathrm{s} 2$ driving rate, \#10 tooth. (b) Real-time stress status with circumferential misalignment $\varphi=0.02^{\circ}$ under $0.5 \mathrm{~m} / \mathrm{s} 2$ driving rate, \#10 tooth. (c) Real-time stress status with circumferential misalignment $\varphi=0.04^{\circ}$ under $0.5 \mathrm{~m} / \mathrm{s} 2$ driving rate, $\# 10$ tooth. 
case, the stress pattern and dynamic characteristics remain similar to the perfect assemble case due to the identical change of all tooth clearance.

\section{Data Availability}

The data used to support the findings of this study are included within the article and are available from the corresponding author upon request.

\section{Conflicts of Interest}

The authors declare that there are no conflicts of interest regarding the publication of this paper.

\section{Acknowledgments}

This research was funded by the National Natural Science Foundation of China, grant no. 52075032, and Major Systematic Project of China Railway, grant no. P2019J002.

\section{References}

[1] A. Barrot, M. Paredes, and M. Sartor, "Determining both radial pressure distribution and torsional stiffness of involute spline couplings," Proceedings of the Institution of Mechanical Engineers, Part C: Journal of Mechanical Engineering Science, vol. 220, no. 12, pp. 1727-1738, 2006.

[2] A. Barrot, M. Paredes, and M. Sartor, "Extended equations of load distribution in the axial direction in a spline coupling," Engineering Failure Analysis, vol. 16, no. 1, pp. 200-211, 2009.

[3] A. Barrot, M. Sartor, and M. Paredes, "Investigation of torsional teeth stiffness and second moment of area calculations for an analytical model of spline coupling behaviour," Proceedings of the Institution of Mechanical Engineers, Part C: Journal of Mechanical Engineering Science, vol. 222, no. 6, pp. 891-902, 2008.

[4] B. P. Volfson, "Stress sources and critical stress combinations for splined shaft," Journal of Mechanical Design, vol. 104, no. 3, pp. 551-556, 1982.

[5] K. W. Chase, C. D. Sorensen, and B. J. K. DeCaires, "Variation analysis of tooth engagement and loads in involute splines," IEEE Transactions on Automation Science and Engineering, vol. 7, no. 4, pp. 746-754, 2009.

[6] S. Medina and A. V. Olver, "Regimes of contact in spline couplings," Journal of Tribology, vol. 124, no. 2, pp. 351-357, 2002.

[7] S. Medina and A. V. Olver, "An analysis of misaligned spline couplings," Proceedings of the Institution of Mechanical Engineers, Part J: Journal of Engineering Tribology, vol. 216, no. 5, pp. 269-278, 2002.

[8] R. A. Adey, J. Baynham, and J. W. Taylor, "Development of analysis tools for spline couplings," Proceedings of the Institution of Mechanical Engineers, Part G: Journal of Aerospace Engineering, vol. 214, no. 6, pp. 347-357, 2000.

[9] S. B. Leen, I. J. Richardson, I. R. McColl, E. J. Williams, and T. R. Hyde, "Macroscopic fretting variables in a splined coupling under combined torque and axial load," The Journal of Strain Analysis for Engineering Design, vol. 36, no. 5, pp. 481-497, 2001.

[10] S. B. Leen, T. H. Hyde, C. H. H. Ratsimba, E. J. Williams, and I. R. McColl, "An investigation of the fatigue and fretting performance of a representative aero-engine spline coupling," The Journal of Strain Analysis for Engineering Design, vol. 37, no. 6, pp. 565-583, 2002.

[11] S. B. Leen, I. R. McColl, C. H. H. Ratsimba, and E. J. Williams, "Fatigue life prediction for a barrelled spline coupling under torque overload," Proceedings of the Institution of Mechanical Engineers, Part G: Journal of Aerospace Engineering, vol. 217, no. 3, pp. 123-142, 2003.

[12] J. Hong, D. Talbot, and A. Kahraman, "Load distribution analysis of clearance-fit spline joints using finite elements," Mechanism and Machine Theory, vol. 74, pp. 42-57, 2014.

[13] J. Hong, D. Talbot, and A. Kahraman, "A semi-analytical load distribution model for side-fit involute splines," Mechanism and Machine Theory, vol. 76, pp. 39-55, 2014.

[14] J. Hong, D. Talbot, and A. Kahraman, "Effects of tooth indexing errors on load distribution and tooth load sharing of splines under combined loading conditions," Journal of Mechanical Design, vol. 137, p. 3, 2015.

[15] L. Limmer, D. Nowell, and D. A. Hills, “A combined testing and modelling approach to the prediction of the fretting fatigue performance of splined shafts," Proceedings of the Institution of Mechanical Engineers, Part G: Journal of Aerospace Engineering, vol. 215, no. 2, pp. 105-112, 2001.

[16] A. Tjernberg, "Load distribution in the axial direction in a spline coupling," Engineering Failure Analysis, vol. 8, no. 6, pp. 557-570, 2001.

[17] A. Tjernberg, "Load distribution and pitch errors in a spline coupling," Materials \& Design, vol. 22, no. 4, pp. 259-266, 2001.

[18] F. Curà and A. Mura, "Experimental procedure for the evaluation of tooth stiffness in spline coupling including angular misalignment," Mechanical Systems and Signal Processing, vol. 40, no. 2, pp. 545-555, 2013.

[19] X. Hu, B. Hu, F. Zhang, B. Fu, H. Li, and Y. Zhou, "Influences of spline assembly methods on nonlinear characteristics of spline-gear system," Mechanism and Machine Theory, vol. 127 , pp. 33-51, 2018.

[20] M. Amarnath, C. Sujatha, and S. Swarnamani, "Experimental studies on the effects of reduction in gear tooth stiffness and lubricant film thickness in a spur geared system," Tribology International, vol. 42, no. 2, pp. 340-352, 2009.

[21] R. G. Munro1, D. Palmer, and L. Morrish, "An experimental method to measure gear tooth stiffness throughout and beyond the path of contact," Proceedings of the Institution of Mechanical Engineers, Part C: Journal of Mechanical Engineering Science, vol. 215, no. 7, pp. 793-803, 2001.

[22] K. L. Johnson, Contact Mechanics, Cambridge University Press, Cambridge, England, 2004.

[23] P. Velex and V. Cahouet, "Experimental and numerical investigations on the influence of tooth friction in spur and helical gear dynamics," Journal of Mechanical Design, vol. 122, no. 4, pp. 515-522, 2000.

[24] F. Curà, A. Mura, and P. S. d. Ugarte Sevilla, "Recent advances in spline couplings reliability," Procedia Structural Integrity, vol. 19, pp. 328-335, 2019. 
[25] J. Wang, T. C. Lim, and M. Li, "Dynamics of a hypoid gear pair considering the effects of time-varying mesh parameters and backlash nonlinearity," Journal of Sound and Vibration, vol. 308, no. 1-2, pp. 302-329, 2007.

[26] W. D. Weatherford Jr, M. L. Valtierra, and P. M. Ku., "Mechanisms of wear in misaligned splines," Journal of Lubrication Technology, vol. 90, no. 1, pp. 42-48, 1968.

[27] J. Ding, I. R. McColl, and S. B. Leen, "The application of fretting wear modelling to a spline coupling," Wear, vol. 262, no. 9-10, pp. 1205-1216, 2007.

[28] Y. Guo, S. Lambert, R. Wallen, R. Errichello, and J. Keller, "Theoretical and experimental study on gear-coupling contact and loads considering misalignment, torque, and friction influences," Mechanism and Machine Theory, vol. 98, pp. 242-262, 2016. 